\title{
High strength steel square and rectangular tubular stub columns infilled with concrete
}

DOI:

10.1016/j.jcsr.2021.106536

\section{Document Version}

Accepted author manuscript

Link to publication record in Manchester Research Explorer

\section{Citation for published version (APA):}

Cai, Y., Su, M., Chen, X., \& Young, B. (2021). High strength steel square and rectangular tubular stub columns infilled with concrete. Journal of Constructional Steel Research, 179, [106536].

https://doi.org/10.1016/j.jcsr.2021.106536

\section{Published in:}

Journal of Constructional Steel Research

\section{Citing this paper}

Please note that where the full-text provided on Manchester Research Explorer is the Author Accepted Manuscript or Proof version this may differ from the final Published version. If citing, it is advised that you check and use the publisher's definitive version.

\section{General rights}

Copyright and moral rights for the publications made accessible in the Research Explorer are retained by the authors and/or other copyright owners and it is a condition of accessing publications that users recognise and abide by the legal requirements associated with these rights.

\section{Takedown policy}

If you believe that this document breaches copyright please refer to the University of Manchester's Takedown Procedures [http://man.ac.uk/04Y6Bo] or contact uml.scholarlycommunications@manchester.ac.uk providing relevant details, so we can investigate your claim.

\section{OPEN ACCESS}


Cai, Y.C., Su, M.N., Chen X.R., Young B. (2021), "High Strength Steel Square and Rectangular Tubular Stub Columns Infilled with Concrete”, Journal of Constructional Steel Research, 179, 106536.

\title{
High Strength Steel Square and Rectangular Tubular Stub Columns Infilled
} with Concrete

\author{
Yancheng Cai ${ }^{a}$, Meini Su ${ }^{\text {b,* }}$, Xuerui Chen ${ }^{b}$, Ben Young ${ }^{\text {a }}$ \\ a Department of Civil and Environmental Engineering, The Hong Kong Polytechnic University, Hong Kong, China \\ (Formerly, Department of Civil Engineering, The University of Hong Kong, Pokfulam Road, Hong Kong, China) \\ b Department of Mechanical, Aerospace, and Civil Engineering, The University of Manchester, Manchester, UK
}

Abstract: This paper presents the experimental and numerical investigations of high strength steel square and rectangular tubular stub columns infilled with concrete. Firstly, a series of tests was conducted on cold-formed high strength steel (CFHSS) square and rectangular tubular sections infilled with three different concrete compressive strengths, i.e., 40, 80 and $120 \mathrm{MPa}$. The CFHSS tubular sections had the nominal $0.2 \%$ proof stress (yield stress) up to $900 \mathrm{MPa}$. Secondly, an extensive numerical study accounting for the confinement effect, as well as the non-linearities of materials, geometry and contacts was performed. Upon validation against the test results, a parametric investigation was conducted. The structural behaviour of concrete-filled CFHSS stub columns was investigated, including the ultimate load, end shortening, strength enhancement index and ductility index. Finally, the experimental and numerical results were used to assess the suitability of the design rules specified in the current American Specification (AISC) and European Code (EC4) for the compressive strength of the concrete-filled CFHSS square and rectangular stub columns. It was found that the predictions from EC4 were generally unconservative while those from the AISC were conservative. However, the predictions by EC4 became conservative if the effective strength of infilled concrete or the effective area of outer steel tubes were considered in the design. In addition, the predictions by EC4 became less scattered for different infilled concrete strengths when the effective concrete strengths were used. However, using the effective concrete strengths or the effective areas did not lead to the improvements of for the AISC specifications.

Keywords: Concrete-filled steel tube; experimental investigation; high strength steel; numerical investigation; square and rectangular hollow sections.

\footnotetext{
"Corresponding author.
}

E-mail address: Meini.su@manchester.ac.uk 
42 Concrete-filled steel tubular (CFST) members have been used widely in the construction industry for their excellent structural performance. They have been used as mega columns in super high-rise buildings [1], chord members in composite arch bridges [2], piles in floodwall structures [3], bridge piers [4] as well as submarine pipeline structures [5-6]. Their excellent structural performance is mainly benefited from the synergistic interactions between the inner concrete and the outer steel tube; for example, the steel tube provides confinement to the infilled concrete while the infilled concrete prevents the inward buckling and delays the local buckling of the steel tube [7]. These contribute to the structural behaviour of the concrete-filled members, e.g., increased bearing capacity and ductility for concrete-filled steel columns under axial loading condition. Hence, CFST steel columns may provide more economic efficiency than pure structural steel or reinforced concrete columns due to the reduced column size and increased effective space in buildings [8-9].

In the last few decades, experimental, numerical and analytical investigations have been carried out on the structural behaviour and practical applications of CFST columns under various loading conditions, as summarized in the recent literature [9-16]. There are two common methods to improve the load resistance of CFST columns [17] - by increasing the cross-section areas or using high strength materials. The first method might be impractical or uneconomic because the increased area will induce larger structural weight with less usable area and subsequently increase the cost of foundation. The second method of using high strength materials such as high strength steel and concrete could be a more effective way. In addition, the use of high strength steel allows for larger strain ranges of elastic behaviour and thus improving the confinement to the infilled concrete core [9].

With the advancements in material and fabrication techniques, high strength steels and concrete become available nowadays, for examples, in terms of the yield stress $\left(f_{y}\right)$ of steel tubes greater than $1100 \mathrm{MPa}$ [18] and the compressive strength of concrete $\left(f_{c k}\right)$ up to $190 \mathrm{MPa}$ [19]. These developments in individual constituent components have driven the investigations on the behaviour and design of higher performance composite structures, such as high strength steel tubes infilled with high strength concrete [17, 19-21]. A recent review by Liew et al. [9] on the CFST columns with over 2030 test results showed that more than $70 \%$ of the test data using normal strength concrete with $f_{c k}$ not greater than $50 \mathrm{MPa}$, and over $90 \%$ of the data using mild steel with $f_{y}$ not greater than $460 \mathrm{MPa}$. It should be noted that, up to date, investigations on the high strength steel tubes infilled with high strength concrete are relatively limited.

Design of CFST columns are available in current international design specifications, such as the "Eurocode 4: Design of Composite Steel and Concrete Structures - Part 1.1: General Rules and Rules for Buildings" (EC4) [22], the American Specification for Structural Steel Buildings (AISC) [23], the Japanese specification of "Recommendations for design and construction of concrete filled steel tubular structures" (AIJ) [24] and Australian/New Zealand Standard of "Composite structures Composite steel-concrete construction in buildings" (AS/NZS2327) [25]. It should be noted that limitations of the design rules are specified in these specifications, in particular on the yield stress of steel and the compressive strength of concrete. However, the design of high strength square and 
rectangular steel tubes infilled with high strength concrete are not explicitly specified in these design codes [22-25], for example, for columns with $f_{y} \geq 900 \mathrm{MPa}$ and $f_{c k} \geq 80 \mathrm{MPa}$. This will be discussed further in the later section of this paper.

In this study, experimental and numerical investigations were carried out on the structural behaviour of concrete-filled cold-formed high strength steel (CFHSS) square and rectangular stub columns. Firstly, a comprehensive test program consisting of 34 specimens was carried out. The specimens were designed with CFHSS square and rectangular tubes infilled with three different compressive cylinder strengths $(40,80$ and $120 \mathrm{MPa})$ of concrete. The CFHSS tubular sections had the nominal $0.2 \%$ proof stress $\left(f_{0.2}\right)$ up to $900 \mathrm{MPa}$. The test specimens were subjected to uniform axial compression. The ultimate loads and failure modes were obtained. Secondly, an extensive numerical study accounting for the confinement effect, as well as the non-linearities of materials, geometry and contacts was performed. After a successful model validation against test results, a parametric study was conducted by using the validated numerical model. The specimens in the parametric study were designed to cover a wide range of the cross-section dimensions and section slenderness of the CFHSS tubes that infilled with different strengths of concrete. The structural behaviour of concrete-filled CFHSS stub columns was investigated, including the ultimate load, end shortening, strength enhancement index and ductility index. Finally, the experimental and numerical results were used to assess the suitability of the design rules specified in the current international specifications (EC4 [22] and AISC360-10 [23]).

\section{Test program}

\subsection{Material properties}

The CFHSS square and rectangular tubes were used as the outer skin of the concrete-filled steel stub column specimens. The nominal dimensions $(H \times B \times t)$ of the steel tubes were $80 \times 80 \times 4.0 \mathrm{~mm}$, $100 \times 50 \times 4.0 \mathrm{~mm}, 100 \times 100 \times 4.0 \mathrm{~mm}, 120 \times 120 \times 4.0 \mathrm{~mm}, 140 \times 140 \times 5.0 \mathrm{~mm}$ and $160 \times 160 \times 4.0 \mathrm{~mm}$, where $H, B$ and $t$ are the outer depth, width and thickness of the tubes, respectively, as illustrated in Figure 1. The steel tubes of $80 \times 80 \times 4.0 \mathrm{~mm}$ and $100 \times 100 \times 4.0 \mathrm{~mm}$ had the nominal $0.2 \%$ proof stress $\left(f_{0.2}\right)$ of 700 and $900 \mathrm{MPa}$, the steel tubes of $100 \times 50 \times 4.0 \mathrm{~mm}, 140 \times 140 \times 5.0 \mathrm{~mm}$ and $160 \times 160 \times 4.0$ $\mathrm{mm}$ had the $f_{0.2}$ of $700 \mathrm{MPa}$ and the steel tubes of $120 \times 120 \times 4.0 \mathrm{~mm}$ had the $f_{0.2}$ of $900 \mathrm{MPa}$. The CFHSS tubes were divided into two groups based on the nominal value of $f_{0.2}$, as shown in Table 1 , where in the tube labelling, the letter " $\mathrm{A}$ " followed the hyphen of the section legend represents $f_{0.2}=$ $700 \mathrm{MPa}$, and the letter "B" stands for $f_{0.2}=900 \mathrm{MPa}$.

The coupons were machined from the tubes at $90^{\circ}$ angle from the weld. The nominal gauge length and width of the tensile coupons were $25 \mathrm{~mm}$ and $6 \mathrm{~mm}$, respectively [18]. The coupon specimens were tested in a 50-kN MTS testing machine. Two linear strain gauges were adhered on both faces at the middle of the coupon. An extensometer was mounted on the coupons over a gauge length of 25 $\mathrm{mm}$. Displacement control test method was used with loading rates of $0.05 \mathrm{~mm} / \mathrm{min}$ and $0.5 \mathrm{~mm} / \mathrm{min}$ for the elastic range and plastic range, respectively. The results from the strain gauges were used to 
determine the Young's modulus $\left(E_{s}\right)$ of the coupon specimens. The stress-strain curves of the CFHSS tubular members are shown in Figures 2(a)-(b) for the members with nominal $f_{0.2}$ of $700 \mathrm{MPa}$ and $900 \mathrm{MPa}$, respectively. The rest of the material properties were determined from the stress-strain curves that measured by the extensometer. The results from coupon tests are presented in Table 1, including the $E_{s}, f_{0.2}$, the ultimate strength $\left(f_{u}\right)$, the strain at ultimate $\left(\varepsilon_{u}\right)$, and the strain at fracture $\left(\varepsilon_{f}\right)$.

Three different mixes of concrete $(\mathrm{C} 40, \mathrm{C} 80$ and $\mathrm{C} 120)$ with the respective nominal compressive cylinder strengths $\left(f_{c k}\right)$ of $40 \mathrm{MPa}, 80 \mathrm{MPa}$ and $120 \mathrm{MPa}$ were prepared to infill the steel tubes. Concrete cylinders were prepared to determine the concrete strengths. The concrete cylinder had the nominal diameter of $150 \mathrm{~mm}$ and height of $300 \mathrm{~mm}$. The cylinder tests were conducted in accordance with the procedures in the ACI [26]. Two series of cylinder compression tests were conducted to obtain the cylinder strength $\left(f_{c k}\right)$, one on the 28th day after casting and the other on the date of the corresponding stub column tests [27]. The average test results of the different concrete mixes are presented in Table 2.

\subsection{Test specimens}

A series of concrete-filled CFHSS square and rectangular stub column specimens were designed by using the aforementioned seven types of CFHSS tubes (Table 1) as the outer skin. Each series of tubes were infilled with those three different mixes of concrete (Table 2), namely, C40, C80 and C120. In addition, to reflect the effects of infilled concrete in the same specimen series, the CFHSS square and rectangular stub columns without infilled concrete were also designed. Hence, there are 34 stub column specimens in this study, including two repeated specimens, as shown in Tables 3-4 for the steel grades of outer tubes in Series A and B, respectively. The parameters of the specimens mainly included the variations of $H / B=1.0$ and 2.0, $h / t$ ranging from 15.1 to 35.3 ( $h$ represents the flat portion of the section height), the two steel grades (Series A and B) and the three different strengths of concrete infill. The nominal length $(L)$ of each CFHSS tube was taken as $3 D$ in order to make sure that each specimen would not fail by overall buckling. The mean values of the measured section dimensions and lengths of the tubular stub column specimens were summarized in Tables 3-4. All the steel square and rectangular tubes were wire cut at both ends before infilling concrete. Concrete of different strengths was then cast into the steel tubes and vibrator was also used in the casting process.

The stub column specimens were labelled by distinguishing their nominal section dimensions, nominal concrete cylinder strengths and the steel grades of outer tubes. For example, Specimen $100 \times 100 \times 4-\mathrm{C} 40$-A, the first segment of $100 \times 100 \times 4(H \times B \times t)$ indicates that the nominal section dimensions of the outer tube, and the symbol following the hyphen indicates the steel tube is infilled with concrete having the nominal cylinder compressive strength of $40 \mathrm{MPa}$. It should be noted that the symbol "C0" means there is no infilled concrete, namely, it is a CFHSS stub column specimen with hollow section. The last segment represents the nominal strengths of the steel tubes, where " $A$ " and " $\mathrm{B}$ " for the $f_{0.2}$ of $700 \mathrm{MPa}$ and $900 \mathrm{MPa}$, respectively, as mentioned earlier. If it is a repeated test, it is indicated by a letter " $\mathrm{r}$ " in the end of the label. The details of the concrete-filled CFHSS square and rectangular tubular stub column specimens are shown in Tables 3-4. 
158 Tests of the concrete-filled CFHSS tubular stub columns were conducted in the Structural Laboratory at The University of Hong Kong. Figure 3 illustrates a typical test setup. A $5000 \mathrm{kN}$ capacity servocontrolled hydraulic testing machine was used to apply axial compressive force to the concrete-filled CFHSS stub column specimens. Three 50-mm range Linear Voltage Differential Transducers (LVDTs)

162

163

164

165

166

167

168

169

170

171

172

173

174

175

176

177

178

179

180

181

182

183

184

185

186

187

188

189

190

191

192

193

194 were used to measure the end shortening of the specimens. These three LVDTs were placed between the top and bottom bearing plates at evenly located positions. To prevent "elephant foot" failure, endstiffeners (steel frames) with height of around $25 \mathrm{~mm}$ were used near each end of the column prior to testing. It should be noted that, for the stub columns infilled with concrete, the top surface of the column might not be at the same level as the end of the steel tube due to shrinkage of the concrete. Hence, plaster materials were used to fill the small gap between the steel tube and infilled concrete [27], as illustrated in Figure 4.

A special ball bearing was used at the top end of the specimen. An initial load of around $2 \mathrm{kN}$ was applied to the specimens. During pre-loading, any possible gaps between the specimen and the contacting surfaces of the testing machine were eliminated. The bearing was then locked after preloading. Hence, the load was applied uniformly across the whole composite cross-section. Compressive load was applied by displacement control to the specimens with a constant rate of 0.2 $\mathrm{mm} / \mathrm{min}$ using the servo-controlled hydraulic testing machine. By using this test method, the tests could be continued after experiencing the peak loads. The stub column tests were stopped when clear drops of axial loads were observed. A data logger was used to record the readings from the LVDTs and loads at the interval of 1 second. The load-end shortening responses of the test specimens were thus obtained.

\subsection{Test results}

The compressive behaviour of the stub columns was observed during the tests. The ultimate load $\left(P_{t}\right)$ of the specimen and the corresponding end-shortening $\left(\delta_{u}\right)$, as well as the end-shortening $\left(\delta_{u, 0.85}\right)$ at $0.85 P_{t}$ after each specimen experienced its ultimate load are shown in Tables 5-6, for CFHSS series A and B, respectively. The applied load versus axial end-shortening relationship was obtained for each column specimen (e.g., curves in Figures 5(a)-(d)), where the applied load was recorded from the actuator and the end-shortening was taken as the average readings of three LVDTs. Two repeated tests were conducted (i.e. $100 \times 50 \times 4-C 40-A-r$ and $120 \times 120 \times 4-C 80-B-r$ ), and the ultimate loads of the repeated tests were very close to their respective first test results, with a maximum difference of $1.9 \%$. This small difference indicated the reliability of the test results. The ultimate loads $\left(P_{t}\right)$ of the concrete-filled stub column specimens were normalized with those $\left(P_{t, 0}\right)$ without infilled concrete for the same series, indicated by the abbreviation of "Nor.", as shown in Tables 5-6. It is clearly shown that the ultimate loads of the tubular specimens were significantly improved by the infilled concrete in this study, for examples, up to $326 \%$ for Series $160 \times 160 \times 4-A$ and up to $211 \%$ for Series $120 \times 120 \times 4-B$. 
All the concrete-filled CFHSS square and rectangular stub columns failed by the crushing of the infilled concrete together with outward buckling of the steel tubes at some locations. It should be noted that the use of steel frames at the ends of the columns was able to prevent the "elephant foot" failure of the specimens. The local buckling failure was observed for all specimens. The inward and outward local buckling behaviour was found in specimens without infilled concrete, i.e., specimens of $80 \times 80 \times 4-\mathrm{C} 0-\mathrm{A}, 100 \times 50 \times 4-\mathrm{C} 0$-A (see Figure 6), $100 \times 100 \times 4-\mathrm{C} 0-\mathrm{A}, \quad 140 \times 140 \times 5-\mathrm{C} 0-\mathrm{A}$, $160 \times 160 \times 4-\mathrm{C} 0-\mathrm{A}, 80 \times 80 \times 4-\mathrm{C} 0-\mathrm{B}, 100 \times 100 \times 4-\mathrm{C} 0-\mathrm{B}$ and $120 \times 120 \times 4-\mathrm{C} 0-\mathrm{B}$. However, the inward local buckling phenomenon was not observed in all concrete-filled CFHSS square and rectangular stub columns, as it was prevented by the infilled concrete in the steel tubes. Figures 6-7 further illustrate the failure modes of the tested concrete-filled CFHSS rectangular stub column Series $100 \times 50 \times 4$-A and square stub column series $80 \times 80 \times 4$-A and $80 \times 80 \times 4$-B.

\section{Finite element analysis}

\subsection{Development of model}

Finite element model (FEM) was developed to simulate the tests of concrete-filled CFHSS square and rectangular stub column specimens. A finite element analysis software ABAQUS [29] was used to develop the FEM. The measured specimen dimensions (Tables 3-4), and material properties of the steel (Table 1) and concrete (Table 2) presented in Section 2 of this paper were used in the analysis of FEM.

The steel tube and concrete core were assigned by the S4R (four-node shell element with reduced integration) and the C3D8R (8-node linear brick element with reduced integration and hourglass control), respectively. Based on the mesh convergence study, the element mesh size of $(B+D) / 30$ for the steel tube and $(B+D) / 15$ for the concrete core was used. The engineering stress-strain $(\sigma-\varepsilon)$ curve was converted to a true stress $\left(\sigma_{\text {true }}\right)$ and logarithmic plastic strain $\left(\varepsilon_{\text {true }}^{p l}\right)$ curve, by using the following Equations (1)-(2):

$$
\begin{aligned}
& \sigma_{\text {true }}=\sigma(1+\varepsilon) \\
& \varepsilon_{\text {true }}^{p l}=\ln (1+\varepsilon)-\frac{\sigma_{\text {true }}}{E_{S}}
\end{aligned}
$$

The true stress-true plastic strain curves were simplified by means of a piecewise linear stress-strain model, in particular, over the strain-hardening region.

The interactive behaviour between the steel tube and concrete was simulated using the interaction algorithm in ABAQUS [29]. The inner surface of the steel tube and the outer surface of the infilled concrete were defined to be a contact pair, of which the former acted as slave surface and the latter acted as master surface. Previous investigations [30] have shown that a friction coefficient from 0.1 to 0.5 generally causes limited effect on the prediction of the ultimate strength, but a smaller friction factor may induce a convergent problem with large deformation. It should be noted that different friction coefficients have been used in literature, for examples, coefficients of 0.25 [31], 0.3 [32] and 
0.6 [33]. In the present study, the friction factor of 0.25 in the tangential direction between the concrete and steel was employed, while the "hard contact" behaviour in the normal direction was assumed with no penetration allowed between the surfaces.

234 Local imperfections were considered in the FEM of the square and rectangular tubular stub column 235 specimens without infilled concrete (specimens of $80 \times 80 \times 4-\mathrm{C} 0-\mathrm{A}, 100 \times 50 \times 4-\mathrm{C} 0-\mathrm{A}, 100 \times 100 \times 4-\mathrm{C} 0$ A, $140 \times 140 \times 5-C 0-A, 160 \times 160 \times 4-C 0-A, 80 \times 80 \times 4-C 0-B, 100 \times 100 \times 4-C 0-B$ and $120 \times 120 \times 4-C 0-B$ ), as those FEM for CFHSS square and rectangular tubular stub columns performed by Ma et al. [34]. However, local imperfections of steel tubes for concrete-filled CFHSS square and rectangular stub columns were not considered. This is because the influence of local imperfections on the behaviour of concrete-filled steel stub columns is negligible due to the infilled concrete. This has been proved by the sensitivity study for the effects of imperfections on the structural behaviour of concrete-filled stainless steel and carbon steel tubular stub columns, as detailed in Tao et al. [35-36]. Hence, unlike the FEM for CFHSS square and rectangular tubular stub columns [34], the initial imperfections of steel tubes were not considered in the FEM for the concrete-filled CFHSS stub columns in the present study.

246

A reference node located at the centroid of the cross-section for each column end was defined. The reference node was coupled with the corresponding cross-section at each column end in displacements and rotations. The reference nodes were restrained against all degrees of freedom, except for the longitudinal displacement (along the length direction of the stub column) at the loading point. A specified axial displacement was assigned to the reference node at the loading point. General Static analysis step was adopted [29]. Hence, the adopted displacement control method in the tests was simulated in the FEM analyses. The nonlinear geometric parameter (NLGEOM) was enabled to deal with the large displacement analysis.

\subsection{Stress-strain of the confined concrete model}

The lateral expansion of the infilled concrete is confined by the outer steel tube when the stub columns subjected to axial compression. This confinement helps to increase the strength and ductility of concrete, which refers as "composite action" between the steel tube and infilled concrete [37]. In this study, the confined model of concrete proposed by Tao et al. [38] was adopted in the FEM.

The key parameters in determining the "concrete damaged plasticity" of the confined concrete model were summarized in the following. The dilation angle $(\psi)$ was assumed to be a constant value of $40^{\circ}$ for concrete filled steel stub square and rectangular columns, as suggested by Tao et al. [38]. The flow potential eccentricity and viscosity parameters were taken as -1.0 and 0 , respectively. The ratio of the compressive strength under biaxial loading to uniaxial compressive strength $f_{b o} / f_{c k}$ was determined by $1.5 f_{c k}^{-0.075}$, as suggested by Papanikolaou and Kappos [39]. Hence, in the validation of the FEM, the actual ratios of $f_{b o} / f_{c k}$ for concrete of C40, C80 and C120 were taken as 1.148, 1.074 and 1.051, respectively, based on the respective measured compressive strengths of $35.5 \mathrm{MPa}, 85.7$ $\mathrm{MPa}$ and 114.9 $\mathrm{MPa}$, as shown in Table 2. The ratio of the second stress invariant on the tensile 
meridian to that on the compressive meridian $(K)$ is one of the important parameters for determining the yield surface of concrete plasticity model. It is commonly taken from 0.5 to 1.0 by the researchers while the default value is $2 / 3$ in ABAQUS [29]. In this study, the equation proposed by $\mathrm{Yu}$ et al. [40] was used to calculate the ratio of $K$. Thus, the values of $K$ were $0.72,0.71$ and 0.70 for concrete compressive cylinder strengths of 40, 80 and $120 \mathrm{MPa}$, respectively. In addition, the fracture energy $\left(G_{F}\right)$ was determined based on the reference [41-42], which are $0.068,0.11$ and 0.143 for concrete of C40, C80 and C120, respectively.

As mentioned previously, the stress-strain model (three stages) of the infilled concrete that considering the strain hardening/softening rule of concrete core proposed by Tao et al. [38] was used in this study, as illustrated in the following.

The initial stage $\left(0<\varepsilon \leq \varepsilon_{c}\right)$ of the curve was determined by Equation (3):

$$
\frac{\sigma}{f_{c k}}=\frac{A \cdot X+B \cdot X^{2}}{1+(A-2) X+(B+1) X^{2}} \quad 0<\varepsilon \leq \varepsilon_{c 0}
$$

in which $X=\varepsilon / \varepsilon_{c} ; A=E_{\mathrm{c}} \varepsilon_{c} / f_{c k} ; B=(A-1)^{2} / 0.55-1 ; E_{c}$ is the Young's modulus of the infilled concrete; $\varepsilon_{c 0}$ is the strain at peak stress under uniaxial compression determined by using Equation (4).

$$
\varepsilon_{c 0}=0.00076+\sqrt{\left(0.626 f_{c k}-4.33\right) \times 10^{-7}}
$$

In the second stage $\left(\varepsilon_{c 0}<\varepsilon \leq \varepsilon_{c c}\right)$ of the curve, the relationship of stress-strain was determined by the following Equations (5) and (6):

$$
\frac{\varepsilon_{c c}}{\varepsilon_{c 0}}=e^{k}
$$

$$
k=\left(2.9224-0.00367 f_{c k}\right)\left(\frac{f_{B}}{f_{c k}}\right)^{0.3124+0.002 f_{c}}
$$

where $f_{B}$ represents the confining stress in concrete at strain of $\varepsilon_{c c}$. The confining stress of $f_{B}$ was determined by Equation (7):

$$
f_{B}=\frac{0.25\left(1+0.027 f_{0.2}\right) e^{\frac{-0.02 \sqrt{B^{2}+D^{2}}}{t}}}{1+1.6 e^{-10}\left(f_{c k}\right)^{4.8}}
$$

The last stage $\left(\varepsilon_{c c}<\varepsilon\right)$, i.e., descending branch, of the stress-strain curve was determined by Equation (8):

$$
\sigma=f_{r}+\left(f_{c k}-f_{r}\right) \exp \left[-\left(\frac{\varepsilon-\varepsilon_{c c}}{\alpha}\right)^{\beta} \quad \varepsilon \geq \varepsilon_{c c}\right.
$$

where $f_{r}$ is the residual stress as determined by Equation (9). The parameters $\alpha$ and $\beta$ are the factors that influence the shape of curve.

$$
f_{r}=0.1 f_{c k}
$$

The parameter $\alpha$ is calculated as: 


$$
\alpha=0.005+0.0075 \xi_{c}
$$

299 The parameter $\beta$ is taken as 0.92 for concrete-filled square and rectangular steel stub columns [43].

\subsection{Validation of FEM}

302 Based on the developed FEM by using the measured dimensions and material properties, the modelling parameters as well as the confined concrete model, the analysis of the FE were performed. The developed FEM was validated by comparing the FE results with the test results in terms of the ultimate loads, failure modes and the load-end shortening curves. The comparison of the ultimate loads $\left(P_{t}\right)$ from tests with those $\left(P_{F E A}\right)$ predicted from the $\mathrm{FE}$ analysis are shown in Table 7 . The mean value of the $P_{t} / P_{F E A}$ is 1.00 with the corresponding coefficient of variation $(\mathrm{COV})$ of 0.079 . It is shown that the developed FEM can successfully replicate the ultimate capacities of the concrete-filled CFHSS square and rectangular stub columns. Figures 8-9 illustrate the comparison of load-end shortening curves and failure modes obtained from the test and FEA for specimens $80 \times 80 \times 4-\mathrm{C} 80-\mathrm{A}$ and $120 \times 120 \times 4-\mathrm{C} 120-\mathrm{B}$, respectively. The contributions of the outer steel tubes and the concrete infill in the history of the load-end shortening curves that obtained from the FEA were also plotted in the figures. It is clearly shown that the infilled concrete reached its ultimate load (or first peak) earlier than that of the outer steel tube, as reflected in the smaller end shortening values. However, due to the confinement effect, the load resistance of the infilled concrete may increase as the end shortening increased even the load resistance of the outer steel tube reduced due to local buckling. Generally, it is shown that the end-shortenings $\left(\delta_{u}\right)$ of the concrete-filled CFHSS stub columns at the ultimate loads (or first peaks) were dominated by those of the concrete infill, namely, the values of end shortening for the concrete-filled CFHSS stub columns were close to those of the infilled concrete at the ultimate loads (or first peaks).

\section{Parametric study}

\subsection{Design of specimens}

324 The validated FEM was used to perform a further study on the behaviour of concrete-filled CFHSS square and rectangular stub columns. The parameters that may affect the structural behaviour of the stub columns were considered, including the cross-section dimensions, section slenderness (ratios of $h / t), f_{0.2}$ of the steel tubes (steel grades), compressive strengths of infilled concrete. A total of 52 specimens were carefully designed to cover a wide range of parameters, including 24 for rectangular specimens and 28 for square specimens. The ratios of $h / t$ varied from 35.0 to 75.0 and from 10.0 to 55.0 for rectangular and square tubes, respectively. The stress-strain curves of sections $100 \times 100 \times 4-$ A and $100 \times 100 \times 4-B$ having the respective nominal $f_{0.2}$ of $700 \mathrm{MP}$ and $900 \mathrm{MPa}$ were used. As those of the test specimens, the compressive cylinder strengths $\left(f_{c k}\right)$ of the infilled concrete were 40,80 and $120 \mathrm{MPa}$, respectively, and the length of each stub column was taken to be $3 D$. The dimensions of concrete-filled CFHSS square and rectangular stub columns used in this parametric study are detailed 
in Tables 8-9, respectively. The criterion for the specimen labelling is the same as those described in Section 2.2 of this paper. In this sense, the last letters " $A$ " and " $B$ " in the specimen labelling represent the different steel grades by using stress-strain curves of sections $100 \times 100 \times 4-\mathrm{A}\left(f_{0.2}=700 \mathrm{MPa}\right)$ and $100 \times 100 \times 4-\mathrm{B}\left(f_{0.2}=900 \mathrm{MPa}\right)$, respectively. The CFHSS stub columns without infilled concrete are also included, as distinguished by the segment of "C 0 ".

\subsection{Definition of parameters}

The parametric study of the concrete-filled CFHSS square and rectangular stub columns aims to study its structural behaviour under axial compression. These included the ultimate load, end shortening, the strength enhancement index (SI), as well as the ductility index (DI) [28].

The strength enhancement index (SI), as expressed in Equation (11), is defined by the ratio of the ultimate compressive load $\left(P_{u}\right)$ of the concrete-filled steel tubular stub column to the sum of the strengths of the individual constituent components (i.e., the concrete core and steel tube). The parameter $\boldsymbol{S I}$ reflects the contribution of composite action in concrete-filled CFHSS square and rectangular stub columns. A SI value higher than 1.0 indicates that the positive interaction between the steel hollow section and the concrete core was achieved. The positive interaction benefits from the confinement effect of the concrete core from the steel tube, as well as the contribution of the concrete core to the delay or elimination of the local buckling in the steel tubular hollow section.

$$
\boldsymbol{S I}=P_{u} /\left(f_{0.2} A_{s}+f_{c k} A_{c}\right)
$$

where $A_{s}$ and $A_{c}$ correspond to the cross-section areas of the outer steel tube and the concrete core. The ductility index $(\boldsymbol{D I})$, as expressed in Equation (12), is defined as the ratio of $\delta_{u, 0.85}$ to $\delta_{u}$. The higher value of the parameter $\boldsymbol{D I}$ represents that the better ductility of the specimens.

$$
\boldsymbol{D I}=\delta_{u, 0.85} / \delta_{u}
$$

\subsection{Influence of parameters}

The parametric study results are presented in Tables 8-9, including $P_{F E A}, \delta_{u}$ and $\delta_{u, 0.85}$ for the concretefilled CFHSS square and rectangular stub column specimens. The stub column specimens without infilled concrete (specimens $H \times B \times t$-C0-A and $H \times B \times t$-C0-B), which had the same nominal section sizes as those specimens with the infilled concrete, were also included. In addition, the ultimate loads of the concrete-filled CFHSS square and rectangular stub column specimens were normalized by the ultimate load $\left(P_{F E A, 0}\right)$ of the CFHSS tubular specimen (without infilled concrete) in the same series, as indicated by "Nor." in the Tables 8-9, respectively. The normalized column strengths from the tests and FEA were plotted against the infilled concrete strengths associated with different steel grades (series A and B) and the ratios of $h / t$, as shown in Figures 10(a)-(c). Generally, it is shown that the normalized column strength increased linearly with the increment of the infilled concrete strength for the CFHSS square and rectangular stub column specimens with a given value of $h / t$ (Figures 10(a)- 
371 (c)), where the infilled concrete strength of " 0 " in the horizontal axis means the CFHSS square and 372 rectangular hollow section columns without any infilled concrete. Similar findings have been 373 presented by Su et al. [27] for concrete-filled CFHSS circular tubular stub columns and by Cai et al.

374 [28] for concrete-filled cold-formed and hot-finished steel elliptical tubular stub columns.

375 The behaviour of the concrete-filled CFHSS square and rectangular stub column specimens was investigated in terms of the parameters of $\boldsymbol{S} \boldsymbol{I}$ and $\boldsymbol{D I}$ based on the results from the tests and FEA, as shown in Tables 5-6 and Tables 8-9. Figure 11 presents the relationships between the strength enhancement index $(\boldsymbol{S I})$ and ratios of $h / t$ for stub columns with square sections. As shown in Figure 11 , under a given infilled concrete strength, the value of $\boldsymbol{S I}$ decreased regularly as the value of $h / t$ increased. The decrements for the infilled concrete with nominal $f_{c k}$ of $40 \mathrm{MPa}$ are more obvious than those infilled with nominal $f_{c k}$ of $120 \mathrm{MPa}$. Similar trends were found for those stub column specimens with rectangular sections as illustrated in Figure 12. Furthermore, for the stub columns with square and rectangular sections, it was found that the value of $\boldsymbol{S I}$ generally decreased with the increment of the infilled concrete strength under the same value $h / t$ when $h / t \leq 25.0$; however, when $h / t \geq 25.0$, the value of $\boldsymbol{S I}$ increased with the increment of the infilled concrete strength for a given value of $h / t$, as shown in Figures 11-12. Meanwhile, the values of $\boldsymbol{S I}$ that larger than 1.00 tended to be smaller than 1.00 as the ratio of $h / t$ became larger, e.g., $h / t \geq 35$ for specimens with rectangular sections. One of the main reasons is due to the changing of the section slenderness, a larger value of $h / t$ (i.e., from compact to slender) would fail in local buckling earlier and thus provide less confinement effect to the concrete core, which subsequently decreasing the section capacity.

The ductility indexes (DI) of the CFHSS square and rectangular stub columns with and without infilled concrete were also investigated, as presented in Tables 5-6 and Tables 8-9. As shown in the tables, the values of $\boldsymbol{D I}$ for the concrete-filled CFHSS square and rectangular e stub column specimens were generally higher than those of specimens without infilled concrete, except for those square and rectangular specimens with larger value of $h / t$, e.g., specimens with $h / t=55.0$. This could be due to load resistance drops largely as the failure of local buckling in the outer steel tube occurs. However, these test and FE results indicated that the ductility of the CFHSS square and rectangular stub column specimens could be significantly enhanced by the infilled concrete, as discussed in the Section 1 of this paper.

\section{Existing design rules}

\subsection{General}

403 404 405

Design of concrete-filled steel square and rectangular stub columns are provided by the existing international design specifications [22-25], as mentioned in Section 1 of this paper. It should be noted that concrete grades over C60 are beyond the upper limit of the specified concrete grade in EC4 [22], where the strength classes of the normal weight concrete used in composite members range from $\mathrm{C} 20 / \mathrm{C} 25$ to $\mathrm{C} 50 / \mathrm{C} 60$ only. The design rules provided in EC4 [22] apply to steel grades from S235 $\left(f_{y}\right.$ $=235 \mathrm{MPa})$ to $\mathrm{S} 460\left(f_{y}=460 \mathrm{MPa}\right)$. The design rules specified in AISC [23] are applicable to CFST 
members with $f_{y} \leq 525 \mathrm{MPa}$ and $21 \leq f_{c k} \leq 69 \mathrm{MPa}$. The AIJ Specification [24] allows the steel yield stress and concrete compressive cylinder strength of $440 \mathrm{MPa}$ and $90 \mathrm{MPa}$, respectively while the AS/NZS2327 [25] allows steel yield stress not greater than $690 \mathrm{MPa}$ and concrete cylinder compressive strength in the range of $20 \mathrm{MPa}$ to $100 \mathrm{MPa}$. In the present study, the existing design rules specified in EC4 [22] and AISC [23] were selected to calculate the nominal strengths of concrete-filled CFHSS square and rectangular stub columns. In addition, the recent proposal on the strength reduction of high strength concrete in concrete-filled steel tubular members [8] due to the effects of infilled concrete strength was also incorporated in the calculations, for the nominal strengths predicted by the aforementioned design specifications [22-23].

\subsection{Eurocode 4: Design of Composite Steel and Concrete Structures (EC4)}

EC4 [22] covers the design rules for encased, partially encased and concrete-filled columns both with and without reinforcements. In the present study, no reinforcement was used in the concrete-filled CFHHS stub columns. The compressive design resistance of concrete-filled square and rectangular sections in EC4 [22] is a simple summation of the steel tube and concrete contributions. Account is taken of the higher resistance of the concrete, which is caused by confinement from the outer steel tube, by adopting a concrete coefficient of 1.0, rather than 0.85, as specified in Section 6.7.3.2 in EC4 [22]. The cross-section capacity $\left(P_{E C}\right)$ of a concrete-filled steel square and rectangular tubular stub column is thus given by Equation (13)

$$
P_{E C}=A_{s} f_{0.2}+A_{c} f_{c k}
$$

A slenderness limit of $H / t \leq 52\left(235 / f_{0.2}\right)^{\wedge 0.5}$ for the outer steel tube is specified in the Table 6.3 of EC4 [22]. It should be noted that the yield strength $\left(f_{y}\right)$ of the steel tube was replaced by the $0.2 \%$ proof stress $\left(f_{0.2}\right)$ of the CFHSS stubs in the present study. Beyond the slenderness limit, local buckling needs to be explicitly accounted for, but is not specified in EC4 [22]. Hence, a further investigation was recommended to determine a more appropriate limit for concrete-filled tubes [42]. In this study, for the cross sections exceeding the slenderness limit of $52\left(235 / f_{0.2}\right)^{\wedge 0.5}$, the effective width equations provided in EC3-1.5 [43], as given by the following Equations (14) and (15), were adopted to calculate the effective area of the outer steel tubes.

$$
\rho \leq \frac{\bar{\lambda}_{p}-0.055(3+\varphi)}{\bar{\lambda}_{p}^{2}} \leq 1.0 \text { for } \bar{\lambda}_{p}>0.5+\sqrt{0.085-0.055 \varphi}
$$

where $\rho=$ reduction factor for local buckling for plate buckling; $\varphi$ is the stress ratio which equals to 1.0 in this study; $\bar{\lambda}_{p}$ is the plate slenderness; $k_{\sigma}$ is the buckling factor corresponding to the $\varphi$ and boundary conditions and $k_{\sigma}=4.0$ in this study according to Table 4.1 in EC3-1.5 [43]; $H$ is the flat height of the outer steel tube (replaced by $B$ for the flat width). In the present study, for the test specimens and numerical specimens (shown in Tables 10-11) that exceed the above slenderness limit 
of 52.0, the reduction factor $\rho$ was used in the calculation of the cross-section area instead of the full cross-section area. Similar approach was also adopted by Wang et al. [42] to determine the crosssection strength of concrete-filled double skin rectangular stub columns.

Recently, investigations on the effects of concrete strength for concrete-filled steel short columns revealed that the complexity and severity increased as the infilled concrete strength increased [8]. In particular, it was found that for ultra-high strength concrete with $f_{c k}>90 \mathrm{MPa}$, the increment of concrete strength due to the confinement effect from steel tube should be ignored [9]. Based on the calibrations against the design rules in EC4 [22], a reduction factor $(\eta)$ for the effective compressive strength of the infilled concrete in steel tubes was proposed, as shown in Equation (16). The formula has been used in the predictions of concrete-filled steel tubular stub columns where the effects of infilled concrete strength was considered, such as by Wei et al. [17] and Wang et al. [43]. The reduction factor was also employed in the calculation of concrete-filled steel square and rectangular stub columns in this study when the effects of infilled concrete strengths was considered.

$$
\eta=\left\{\begin{array}{cr}
1.0-\frac{\left(f_{c k}-50\right)}{200} & 50 \mathrm{MPa}<f_{c k} \leq 90 \mathrm{MPa} \\
0.8 & f_{c k}>90 \mathrm{MPa}
\end{array}\right.
$$

\subsection{Specification for Structural Steel Buildings (AISC)}

The nominal compressive strength $\left(P_{A I S C}\right)$ of concrete-filled steel square and rectangular tubular sections under axial loading refers to the design rules specified in Section I2.2b in AISC [23]. For the cross-section strengths of concrete-filled steel square and rectangular stub columns, sections are categorized as compact, non-compact or slender according to the width-to-thickness $(\lambda=h / t)$ ratios of the outer tubes, as specified in Section I1.4 and Table I1.1a of AISC [23]. The value of $P_{\text {AISC }}$ was determined by Equations (17)-(19):

$$
\text { For compact sections }\left(\lambda \leq \lambda_{p}\right) \text {, }
$$

$$
P_{A I S C}=P_{p}
$$

$$
P_{p}=f_{0.2} A_{s}+0.85 f_{c k} A_{c}
$$

$$
\lambda_{p}=2.26 \sqrt{E_{s} / f_{0.2}}
$$

where $P_{p}$ is the compressive strength of compact sections; $\lambda_{p}$ is the slenderness limit for determining whether a section is compact or non-compact.

For non-compact sections $\left(\lambda_{p}<\lambda \leq \lambda_{r}\right)$,

$$
P_{A I S C}=P_{p}-\frac{P_{p}-P_{y}}{\left(\lambda_{r}-\lambda_{p}\right)^{2}}\left(\lambda-\lambda_{p}\right)^{2}
$$

$$
P_{y}=f_{0.2} A_{s}+0.7 f_{c k} A_{c}
$$


where $P_{y}$ is the compressive strength of non-compact sections; $\lambda_{r}$ is the slenderness limit for determining whether a section is non-compact or slender.

For slender sections $\left(\lambda_{r}<\lambda \leq \lambda_{\text {limit }}\right)$,

$$
\begin{aligned}
& P_{n o}=f_{c r} A_{s}+0.7 f_{c k} A_{c} \\
& f_{c r}=9 E_{s}\left(\frac{t}{b}\right)^{2} \\
& \lambda_{\text {limit }}=5.00 \sqrt{E_{s} / f_{0.2}}
\end{aligned}
$$

where $f_{c r}$ is the compressive strength of slender sections. In the present study, all the CFHSS square and rectangular specimens are categorized as compact, non-compact or slender sections based on the above criterion except specimen Series $320 \times 160 \times 4-B$ in the parametric study, whose section slenderness $(\lambda)$ exceeds the limit of $5.00\left(E_{s} / f_{0.2}\right)^{0.5}$. Since the section slenderness beyond this value is not explicitly specified in the AISC [23], the reduction factor in Equation (14) for the effective crosssection area is also adopted in the calculation of the nominal strengths $\left(P_{A I S C}\right)$ for the specimen Series $320 \times 160 \times 4-B$.

\section{Assessment of codified strength predictions}

\subsection{General}

The ultimate load $\left(P_{u}\right)$ from the experimental $\left(P_{t}\right)$ and numerical results $\left(P_{F E A}\right)$ were compared with the nominal strengths predicted by the aforementioned design specifications [22-23], as summarized in Tables 10-11 and Figures 13-16. Comparisons were performed with all safety factors set to unity. In the comparisons, the specimens without infilled concrete were not included, as this study mainly focused on the structural behaviour of concrete-filled CFHSS column specimens with square and rectangular sections.

In the calculation of the nominal strengths (unfactored design strengths) for the test specimens, measured values of the material properties (Table 1) and specimen dimensions (Tables 3-4) were used, which enables a direct comparison between test results and compressive strengths predicted from existing design rules. In calculating the compressive strength of the test specimens, the concrete cylinder strength at the day of the stub column test were used (Table 2). The stress-strain curves of cold-worked materials did not possess sharp yield points. Hence, the measured $0.2 \%$ proof stress $\left(f_{0.2}\right)$ was used as the yield strength $\left(f_{y}\right)$ in calculating the compressive strength for the test specimens. For specimens generated in the parametric study, the measured $f_{0.2}$ of sections $100 \times 100 \times 4-\mathrm{A}$ and $100 \times 100 \times 4-\mathrm{B}$ were used for specimen using steel grades of series $\mathrm{A}\left(f_{0.2}=700 \mathrm{MPa}\right)$ and $\mathrm{B}\left(f_{0.2}=\right.$ $900 \mathrm{MPa}$ ), respectively. The nominal cylinder strengths of the concrete were used. This is because, in the FE model for the parametric study, measured stress-strain curves of the CFHSS sections $100 \times 100 \times 4-A$ and $100 \times 100 \times 4$-B were used together with the stress-strain curves obtained from the confined concrete model that were developed based on nominal concrete strengths. 
514 Table 10 shows the comparison of the test and FE strength-to-predicted strength by EC4 [22] for stub columns with square and rectangular section specimens. The relationships between the comparisons with EC4 [22] and the section slenderness values were plotted in Figures 13-14 for specimens with square and rectangular sections, respectively. Overall, predictions from EC4 [22] were generally unconservative as the mean values for the ratios of the $P_{u} / P_{E C}$ were smaller than 1.00 . As the CFHSS tubular sections became more slender, larger values of $H / t\left(f_{0.2} / 235\right)^{0.5}$, the predictions generally became more unconservative. The modified predicted strength, $P_{E C^{*}}$, represents that effective crosssection area of the steel tube was considered in the calculation of the cross-section area for those sections exceed the slenderness limit of $H / t\left(f_{0.2} / 235\right)^{0.5}=52.0$. Under this circumstance, the predictions by EC4 [22] became conservative, with the mean values of $P_{u} / P_{E C^{*}}$ equalled to 1.07 and 1.09 for specimens with square and rectangular sections, respectively. Furthermore, the coefficients of variation $(\mathrm{COV})$ were significantly reduced, for example in the predictions of specimens with rectangular sections, COV of 0.059 for $P_{u} / P_{E C^{*}}$ compared with that of 0.141 for $P_{u} / P_{E C}$. It means that the consideration of using effective section area for the specimens exceed the slenderness limit in EC4 [22] improved the strength predictions as the predictions became safer and less scattered. As mentioned in Section 5.2, the reduction factor of $\eta$, using Equation (16), for the effective compressive strength of the infilled concrete was also considered in the design predictions, as represented by $P_{E C^{\wedge}}$ in Table 10. It is shown that the predictions were slightly improved as reflected in the mean values $P_{u} / P_{E C^{\wedge}}$ closer to 1.00 with smaller values of $\mathrm{COV}$. The predictions by EC4 [22] were further modified by considering both the reduction factor of $\rho$ for the effective cross-section area of steel tube and the reduction factor of $\eta$ for the effective compressive strength of the infilled concrete, as represented by $P_{E C^{* \wedge}}$ in Table 10 . The predictions by $P_{E C^{* \wedge}}$ became more conservative than those by $P_{E C}, P_{E C^{*}}$ and $P_{E C^{\wedge}}$, as reflected by the largest mean values; however, less scattered predictions were achieved as shown in the smaller values of corresponding COV, which was comparable with those of $P_{u} / P_{E C^{*}}$. The specimens were divided into two groups based on the steel grades of series A and B for the outer steel tubes, it was found that EC4 [22] provided relatively more conservative predictions for those specimens with relatively lower steel grade for both square and rectangular specimens, namely, steel Series A with nominal $f_{0.2}=700 \mathrm{MPa}$.

\subsection{Predictions by the AISC}

Table 11 shows the comparison of the test and FE strength-to-predicted strength by AISC [23] for stub columns with square and rectangular section specimens. The relationships between the comparisons with AISC [23] and the section slenderness values were plotted in Figures 15-16 for square and rectangular specimens, respectively. On the contrary, the predictions from AISC [23] were overall conservative, i.e., the mean values $\left(P_{u} / P_{A I S C}\right)$ of 1.18 and 1.09 for the square and rectangular specimens, respectively. It should be noted that the section slenderness of rectangular specimen Series $320 \times 160 \times 4$-B exceeded the value of $\lambda_{\text {limit }}$ [23], limit of $5.00\left(E_{s} / f_{0.2}\right)^{0.5}$, hence, the reduction factor $\rho$ in Equation (16) was incorporated in the calculation of the cross-section area $\left(A_{s}\right)$ of the steel tube in the strength prediction, as distinguished by “\#” for the values in the bracket in Table 11. Similarly, 
553 the reduction factor of $\eta$ for the effective compressive strength of the infilled concrete was also 554 considered in the design predictions, as represented by modified predictions $P_{A I S C^{\wedge}}$ in Table 11 . It is 555 shown that generally, the modified predictions were not improved for AISC [23]. This may be due to 556 the reduction factor $(\eta)$ was proposed based on the design rules in EC4 [22]. The specimens were also 557 divided into two groups based on the steel grades (i.e. series A and B) for the outer steel tubes. The 558 AISC [23] provided relatively more conservative and more scattered predictions for those specimens 559 with relatively higher steel grade (Series B with $f_{0.2}=900 \mathrm{MPa}$ ) for rectangular specimens, however, 560 relatively more conservative with less scattered predictions were provided for those specimens with 561 relatively lower steel grade (Series A with $f_{0.2}=700 \mathrm{MPa}$ ) for square specimens. Due to the limited 562 numbers of specimens that exceeded the section slenderness limit $\left(\lambda_{\text {limit }}\right)$, the specimens using the 563 effective cross-section area instead of full cross-section area in the calculation were not plotted. As 564 shown in Figures 15-16, for both square and rectangular sections, the predictions by AISC [23] were 565 566 567 568 569 570 571 572

\subsection{Effects of infilled concrete strengths and section slenderness}

Tables 12 (a)-(b) presents the summary of the comparisons between test and FE strengths with codified predictions [22-23] for square and rectangular sections, respectively. In each section type in each table, the specimens were divided by the different strengths of infilled concrete. For the predictions by EC4 [22], it is shown that the predictions were improved for both square and rectangular sections by $P_{u} / P_{E C *}$, safer with less scattered predictions for all the concrete strengths as the effective cross-section areas were used for those slender sections; the predictions also became safer with less scattered predictions by $P_{u} / P_{E C^{\wedge}}$, when the effective strengths were considered for the infilled concrete strengths of 80 and $120 \mathrm{MPa}$. However, when considering both effective crosssection area and effective concrete strengths in the calculation for $P_{u} / P_{E C^{* \wedge}}$, the mean values generally became similar for the different infilled concrete strengths (e.g., mean values of 1.17, 1.16 and 1.16 for infilled concrete of C40, C80 and C120, respectively), which means the effects due to infilled concrete strengths and section slenderness were minimized, as reflected in Figure 13(d) and Figure 14(d). One the contrary, the predictions by the AISC [23], did not show an obvious improvement when the effects due to infilled concrete strengths and section slenderness were taken into consideration, as illustrated in Table 12 and Figures 15-16. For both predictions by EC4 [22] and AISC [23], the predictions were generally more conservative for the lower infilled concrete strengths with less slender sections (non-slender sections), shown in Figures 13(a) and 14(a) for EC4 [22], or more compact sections, shown in Figures 15(a) and 16(a) for AISC [23]. However, the predictions became more conservative (safer) for the higher infilled concrete strengths with more slenderer sections for both EC4 [22] and AISC [23], as shown in Figures 13(a), 14(a), 15(a) and 16(a). 


\section{Conclusions}

593 The structural behaviour of high strength steel square and rectangular tubular stub columns infilled

594

595

596

597

598

599

600

601

602

603

604

605

606

607

608

609

610

611

612

613

614

615

616

617

618

619

620

621

622

623

624

625

626

627

628

629

with concrete has been investigated in the present study. A series of tests was conducted on coldformed high strength steel (CFHSS) square (ranged from $80 \times 80 \mathrm{~mm}$ to $160 \times 160 \mathrm{~mm}$ ) and rectangular $(100 \times 50 \mathrm{~mm})$ tubes infilled with three different grades of concrete (i.e., 40, 80 and $120 \mathrm{MPa})$. The CFHSS tubular sections had the nominal $0.2 \%$ proof stress (i.e. the yield stress) up to $900 \mathrm{MPa}$. A total of 34 test specimens were designed and tested by applying uniform axial compressive loading. An extensive numerical study accounting for the confinement effect, as well as the non-linearities of materials, geometry and contacts have also been performed by using a validated finite element model.

The behaviour of CFHSS square and rectangular stub columns has been investigated, including the compressive capacities, the end shortening, the strength enhancement index $(\boldsymbol{S I})$ and the ductility index $(\boldsymbol{D I})$. The results showed that the ultimate loads of the CFHSS tubular specimens were significantly improved up to $326 \%$ by the infilled concrete in this study. Both the capacities and ductility of the CFHSS square and rectangular stub columns could be significantly enhanced by the infilled concrete. Furthermore, the experimental and numerical results were used to assess the suitability of the design equations specified American Specification (AISC) and European Code (EC4) for the cross-section strength of CFHSS stub columns. Overall, the predictions from EC4 were generally unconservative while the predictions from AISC were conservative. In particular, the predictions were more conservative for the lower infilled concrete strengths with less slender sections (non-slender sections) using EC4 and more compact sections using AISC; however, the predictions became more conservative for the higher infilled concrete strengths with more slenderer sections.

\section{Acknowledgments}

The authors would like to thank the technicians in the Structural Engineering Laboratory at The University of Hong Kong for helping the test program.

\section{References}

[1] Z. Lai, Z. Huang, and A. H. Varma. Seismic analysis and performance of high strength composite special moment frames (C-SMFs). Structures. 9 (2017), 165-178.

[2] W. Huang, Z. Lai, B. Chen, Z. Xie and A. H. Varma. Concrete-filled steel tube (CFT) truss girders: Experimental tests, analysis, and design. Eng. Struct. 156 (2018), 118-129.

[3] Z. Lai and A. H. Varma. Seismic behavior and modeling of circular concrete partially filled spirally welded pipes (CPFSWP). Thin-Walled Struct. 113 (2017), 240-252.

[4] B. Chen, Z. Lai, Q. Yan, A. H. Varma and X. Yu. Experimental behavior and design of CFT-RC short columns subjected to concentric axial loading. J. Struct. Eng. 2017, 04017148.

[5] F. C. Wang, L. H. Han, and W. Li, Analytical behavior of CFDST stub columns with external stainless steel tubes under axial compression.” Thin Walled Struct. 127 (2018) 756-768. 
630 [6] F. C. Wang, and L. H. Han, Analytical behavior of carbon steel-concrete stainless steel double631 skin tube (DST) used in submarine pipeline structure, Mar. Struct. 63 (2019) 99-116.

632 [7] L. H. Han, Concrete-filled steel tubes structure-theory to practice. [In Chinese.]. Beijing: Science 633 Press. 2007.

634 [8] F.-X. Ding, W.-J. Wang, D.-R. Lua and X.-M. Liu. Study on the behavior of concrete-filled square 635 double-skin steel tubular stub columns under axial loading. Structures 23 (2020) 665-676.

636 [9] J.Y. Richard Liew, Mingxiang Xiong and Dexin Xiong. Design of Concrete Filled Tubular Beam637 columns with High Strength Steel and Concrete, Structures, 8 (2), (2016) 213-226.

638 [10] I. Nishiyama, S. Morino, K. Sakino, et al. Summary of research on concrete-filled structural steel 639 tube column system carried out under the US-Japan cooperative research on composite and hybrid 640 structures. Ibaraki Prefecture, Japan: Building Research Institute, 2002.

641 [11] D. K. Kim, A database for composite columns." M.S. thesis, School of Civil and Environmental 642 Engineering, Georgia Institute of Technology, 2005.

643 [12] C. D. Goode, Composite columns-1819 tests on concrete-filled steel tube columns compared 644 with Eurocode 4, Struct. Eng. 86 (16) (2008) 33-38.

645 [13] L. H. Han, W. Li, and R. Bjorhovde, Developments and advanced applications of concrete-filled 646 steel tubular (CFST)structures: Members, J. Constr. Steel Res. 100 (2014) 211-228.

647 [14] Son Thai, H.-T. Thai, B. Uy and T. Ngo, Concrete-filled steel tubular columns: Test database, 648 design and calibration, J. Constr. Steel Res. 157 (2019) 161-181.

649 [15] J. F., Hajjar, B. C. Gourley, C. Tort, M. D. Denavit, P. H. Schiller, and N. Leipziger Mundis, 650 Steel-Concrete Composite Structural Systems, Department of Civil and Environmental Engineering, 651 Northeastern University, Boston, Massachusetts, 2019, $652<$ http://www.northeastern.edu/compositesystems $>$.

653 [16] Lai, Z., and Varma, A. H. High-Strength Rectangular CFT Members: Database, Modeling, and 654 Design of Short Columns. J. Struct. Eng., 2018, 04018036.

655 [17] J. Wei, X. Luo; Z. Lai, and A. H. Varma, Experimental Behavior and Design of High-Strength 656 Circular Concrete-Filled Steel Tube Short Columns, J. Struct. Eng. 146(1) (2019): 04019184.

657 [18] J.-L. Ma, T.-M. Chan and B. Young, Material properties and residual stresses of cold-formed 658 high strength steel hollow sections, J. Constr. Steel Res., 109 (2015) 152-165.

659 [19] M. X. Xiong, D. X. Xiong and J. Y. R. Liew, Axial performance of short concrete filled steel 660 tubes with high- and ultra-high-strength materials, Eng. Struct. 136 (2017) 494-510.

661 [20] K. Sakino, H. Nakahara, S. Morino, and A. Nishiyama, Behaviorof centrally loaded concrete662 filled steel-tube short columns, J. Struct. Eng. 130 (2) (2004) 180-188.

663 [21] M. Khan, B. Uy, Z. Tao, F. Mashiri,Behaviour and design of short high-strength steel welded 664 box and concrete-filled tube (CFT) sections, Eng. Struct. 147 (2017) 458-472.

665 [22] EC4. Eurocode 4: Design of composite steel and concrete structures. 1-1: General rules and rules 666 for buildings control. European Committee for Standardization (CEN) EN 1994-1-1. Brussels, 667 Belgium: CEN, 2004.

668 [23] AISC. Specification for structural steel buildings. AISC 360. Chicago: AISC 2016.

669 [24] AIJ. Recommendations for design and construction of concrete filled steel tubular structures. 670 Architectural Institute of Japan (AIJ), Tokyo, 2008. 
671 [25] AS/NZS2327, Composite structures - Composite steel-concrete construction in buildings, 672 Australian/New Zealand Standard, 2017.

673 [26] ACI, Building Code Requirements for Structural Concrete (ACI 318M-14) and Commentary 674 (ACI 318RM-14), American Concrete Institute, Detroit, USA, 2014.

675 676

[27] M. Su, Y. Cai, X. Chen and B. Young. Behaviour of concrete-filled cold-formed high strength steel circular stub columns. Thin-Walled Structures, 157 (2020) 107078.

[28] Y. Cai, W.M. Quach and B. Young, Experimental and numerical investigation of concrete-filled hot-finished and cold-formed steel elliptical tubular stub columns, Thin-Walled Structures, 145 (2019) 106437.

[29] ABAQUS Analysis User's Manual, ABAQUS, Inc., 2017, Version 6.14.

[30] X. Dai, D. Lam, Numerical modelling of the axial compressive behavior of short concrete-filled elliptical steel columns, J. Constr. Steel Res. 66 (7) (2010) 931-942.

[31] Thai Huu-Tai, Uy Brian, Khan Mahbub, Tao Zhong, Mashiri Fidelis. Numerical modelling of concrete-filled steel box columns incorporating high strength materials. Journal of Constructional Steel Research 102 (2014) 256-265.

[32] Lam D, X. H. Dai, L.H. Han Q. X. Ren and W. Li, Behaviour of inclined, tapered and STS square CFST stub columns subjected to axial load, Thin-Walled Structure, 54 (2012) 94-105.

[33] Al-Ani Yahia Raad. Finite element study to address the axial capacity of the circular concretefilled steel tubular stub columns. Thin-Walled Structures 126 (2018) 2-15.

[34] J.-L. Ma, T.-M. Chan and B. Young, Design of Cold-Formed High-Strength Steel Tubular Stub Columns, J. Struct. Eng., 144(6) (2018) 04018063.

[35] Z. Tao, B. Uy, F.-Y. Liao and L.-H. Han, Nonlinear analysis of concrete-filled square stainless steel stub columns under axial compression, J. Constr. Steel Res. 67 (2011) 1719-1732.

[36] Z. Tao, B. Uy, L.-H. Han and Z.-B. Wang, Analysis and design of concrete-filled stiffened thinwalled steel tubular columns under axial compression, Thin-Walled Struct. 47 (2009) 1544-1556.

[37] L.H. Han, G.H. Yao and Z. Tao, Performance of concrete-filled thin-walled steel tubes under pure torsion, Thin-Walled Struct, 45(1) (2007) 24-36.

[38] Z. Tao, Z. B. Wang and Q. Yu, Finite element modelling of concrete-filled steel stub columns under axial compression, Journal of Constructional Steel Research. 89 (2013) 121-131.

[39] V. K. Papanikolaou and A. J. Kappos, Confinement-sensitive plasticity constitutive model for concrete in triaxial compression, International Journal of Solids and Structures, 44(21) (2007) 70217048

[40] T. Yu, J.G. Teng, Y.L. Wong, and S.L. Dong, Finite element modeling of confined concrete-I: Drucker-Prager type plasticity model, Engineering Structures. 32(3) (2010) 665-679

[41] FIP. CEB-FIP Model Code 1990. London: Thomas Telford Ltd.; 1993.

[42] Z.P. Bažant, E. Becq-Giraudon. Statistical prediction of fracture parameters of concrete and implications for choice of testing standard. Cem Concr Res. 32(4) (2002) 529-56.

[43] F. Wang, B. Young, L. Gardner, Compressive testing and numerical modelling of concrete-filled double skin CHS with austenitic stainless steel outer tubes, Thin-Walled Struct. 141 (2019) 345-359 [44] EC3-1.5. Eurocode 3: Design of steel structures - Part 1-5: Plated structural elements. CEN (European Committee for Standardization). EN 1993-1-5. Brussels, Belgium: CEN, 2006. 
Table 1: Material properties of CFHSS square and rectangular tubes

\begin{tabular}{cccccc}
\hline Tube labelling & $E_{\mathrm{s}}(\mathrm{GPa})$ & $f_{0.2}(\mathrm{MPa})$ & $f_{u}(\mathrm{MPa})$ & $\varepsilon_{u}(\%)$ & $\varepsilon_{f}(\%)$ \\
\hline $80 \times 80 \times 4-\mathrm{A}$ & 211 & 756 & 852 & 3.0 & 16.0 \\
$100 \times 50 \times 4-\mathrm{A}$ & 212 & 721 & 842 & 4.3 & 14.7 \\
$100 \times 100 \times 4-\mathrm{A}$ & 215 & 722 & 819 & 5.7 & 18.0 \\
$140 \times 140 \times 5-\mathrm{A}$ & 210 & 682 & 822 & 6.4 & 21.0 \\
$160 \times 160 \times 4-\mathrm{A}$ & 215 & 629 & 881 & 3.8 & 13.4 \\
\hline $80 \times 80 \times 4-\mathrm{B}$ & 210 & 1022 & 1179 & 1.9 & 11.8 \\
$100 \times 100 \times 4-\mathrm{B}$ & 206 & 980 & 1092 & 1.7 & 12.1 \\
$120 \times 120 \times 4-\mathrm{B}$ & 206 & 991 & 1140 & 2.9 & 12.2 \\
\hline
\end{tabular}

Table 2: Compressive strength $\left(f_{c k}\right)$ of concrete cylinders

\begin{tabular}{ccc}
\hline Concrete mixes & 28 days $(\mathrm{MPa})$ & Column test day $(\mathrm{MPa})$ \\
\hline C40 & 34.9 & 35.5 \\
C80 & 79.9 & 85.7 \\
C120 & 112.7 & 114.9 \\
\hline
\end{tabular}

Note: data source from Ref. [27]. 
Table 3: Dimensions of high strength steel tubes of Series A

\begin{tabular}{cccccc}
\hline Specimens & $H(\mathrm{~mm})$ & $B(\mathrm{~mm})$ & $r_{i}(\mathrm{~mm})$ & $t(\mathrm{~mm})$ & $L(\mathrm{~mm})$ \\
\hline $80 \times 80 \times 4-\mathrm{C} 0-\mathrm{A}$ & 80.6 & 80.2 & 5.0 & 4.00 & 240.0 \\
$80 \times 80 \times 4-\mathrm{C} 40-\mathrm{A}$ & 80.1 & 80.4 & 4.9 & 4.00 & 240.0 \\
$80 \times 80 \times 4-\mathrm{C} 80-\mathrm{A}$ & 80.5 & 80.2 & 5.0 & 3.98 & 240.0 \\
$80 \times 80 \times 4-\mathrm{C} 120-\mathrm{A}$ & 80.7 & 80.2 & 5.0 & 3.96 & 240.0 \\
\hline $100 \times 50 \times 4-\mathrm{C} 0-\mathrm{A}$ & 100.2 & 50.9 & 3.5 & 3.97 & 300.0 \\
$100 \times 50 \times 4-\mathrm{C} 40-\mathrm{A}$ & 100.2 & 50.6 & 3.4 & 3.98 & 300.0 \\
$100 \times 50 \times 4-\mathrm{C} 40-\mathrm{A}-\mathrm{r}$ & 100.2 & 50.7 & 3.5 & 3.96 & 300.0 \\
$100 \times 50 \times 4-\mathrm{C} 80-\mathrm{A}$ & 100.2 & 50.9 & 3.5 & 4.00 & 300.0 \\
$100 \times 50 \times 4-\mathrm{C} 120-\mathrm{A}$ & 100.3 & 50.8 & 3.6 & 3.96 & 299.0 \\
\hline $100 \times 100 \times 4-\mathrm{C} 0-\mathrm{A}$ & 100.6 & 100.8 & 4.3 & 4.00 & 300.0 \\
$100 \times 100 \times 4-\mathrm{C} 40-\mathrm{A}$ & 100.4 & 100.7 & 4.2 & 3.99 & 300.0 \\
$100 \times 100 \times 4-\mathrm{C} 80-\mathrm{A}$ & 100.9 & 100.6 & 4.3 & 3.97 & 300.0 \\
$100 \times 100 \times 4-\mathrm{C} 120-\mathrm{A}$ & 100.8 & 100.5 & 4.3 & 3.96 & 299.5 \\
\hline $140 \times 140 \times 5-\mathrm{C} 0-\mathrm{A}$ & 140.8 & 141.7 & 7.0 & 4.91 & 420.0 \\
$140 \times 140 \times 5-\mathrm{C} 40-\mathrm{A}$ & 141.2 & 140.7 & 7.0 & 4.94 & 420.0 \\
$140 \times 140 \times 5-\mathrm{C} 80-\mathrm{A}$ & 141.0 & 141.4 & 7.1 & 4.97 & 420.0 \\
$140 \times 140 \times 5-\mathrm{C} 120-\mathrm{A}$ & 141.4 & 141.1 & 7.0 & 4.93 & 420.0 \\
\hline $160 \times 160 \times 4-\mathrm{C} 0-\mathrm{A}$ & 161.8 & 161.1 & 6.0 & 4.05 & 480.0 \\
$160 \times 160 \times 4-\mathrm{C} 40-\mathrm{A}$ & 161.2 & 161.7 & 6.0 & 4.01 & 480.0 \\
$160 \times 160 \times 4-\mathrm{C} 80-\mathrm{A}$ & 161.5 & 161.9 & 6.0 & 4.01 & 480.0 \\
$160 \times 160 \times 4-\mathrm{C} 120-\mathrm{A}$ & 162.0 & 161.2 & 6.0 & 4.04 & 480.0 \\
\hline
\end{tabular}


Table 4: Dimensions of high strength steel tubes of Series B

\begin{tabular}{cccccc}
\hline Specimens & $H(\mathrm{~mm})$ & $B(\mathrm{~mm})$ & $r_{i}(\mathrm{~mm})$ & $t(\mathrm{~mm})$ & $L(\mathrm{~mm})$ \\
\hline $80 \times 80 \times 4-\mathrm{C} 0-\mathrm{B}$ & 80.5 & 80.3 & 6.0 & 3.98 & 239.0 \\
$80 \times 80 \times 4-\mathrm{C} 40-\mathrm{B}$ & 80.3 & 80.5 & 6.1 & 3.97 & 240.0 \\
$80 \times 80 \times 4-\mathrm{C} 80-\mathrm{B}$ & 80.5 & 80.2 & 5.8 & 3.99 & 240.0 \\
$80 \times 80 \times 4-\mathrm{C} 120-\mathrm{B}$ & 80.4 & 80.3 & 6.0 & 3.98 & 240.0 \\
\hline $100 \times 100 \times 4-\mathrm{C} 0-\mathrm{B}$ & 100.6 & 100.7 & 7.0 & 4.01 & 300.0 \\
$100 \times 100 \times 4-\mathrm{C} 40-\mathrm{B}$ & 100.6 & 100.6 & 7.0 & 4.00 & 299.5 \\
$100 \times 100 \times 4-\mathrm{C} 80-\mathrm{B}$ & 100.9 & 100.6 & 7.0 & 3.97 & 299.5 \\
$100 \times 100 \times 4-\mathrm{C} 120-\mathrm{B}$ & 100.7 & 100.7 & 7.0 & 3.99 & 299.5 \\
\hline $120 \times 120 \times 4-\mathrm{C} 0-\mathrm{B}$ & 121.8 & 121.6 & 6.0 & 3.93 & 360.0 \\
$120 \times 120 \times 4-\mathrm{C} 40-\mathrm{B}$ & 121.9 & 121.8 & 6.0 & 3.93 & 360.0 \\
$120 \times 120 \times 4-\mathrm{C} 80-\mathrm{B}$ & 121.8 & 121.8 & 6.0 & 3.91 & 359.0 \\
$120 \times 120 \times 4-\mathrm{C} 80-\mathrm{B}-\mathrm{r}$ & 121.9 & 121.8 & 6.0 & 3.93 & 359.0 \\
$120 \times 120 \times 4-\mathrm{C} 120-\mathrm{B}$ & 121.9 & 121.9 & 6.0 & 3.92 & 360.0 \\
\hline
\end{tabular}

791

792

793

794

795

Table 5: Test results of concrete-filled CFHSS stub columns using Series A steel tubes

\begin{tabular}{cccccccc}
\hline Specimens & $H / B$ & $h / t$ & $P_{t}(\mathrm{kN})$ & $\delta_{u}(\mathrm{~mm})$ & $\delta_{0.85 u}(\mathrm{~mm})$ & Nor. & $D I$ \\
\hline $80 \times 80 \times 4-\mathrm{C} 0-\mathrm{A}$ & 1.0 & 15.7 & 1064 & 3.2 & 4.0 & 1.00 & 1.25 \\
$80 \times 80 \times 4-\mathrm{C} 40-\mathrm{A}$ & 1.0 & 15.6 & 1328 & 3.3 & 5.4 & 1.25 & 1.64 \\
$80 \times 80 \times 4-\mathrm{C} 80-\mathrm{A}$ & 1.0 & 15.7 & 1462 & 3.3 & $>9.8$ & 1.37 & $>2.97$ \\
$80 \times 80 \times 4-\mathrm{C} 120-\mathrm{A}$ & 1.0 & 15.8 & 1504 & 3.4 & 6.5 & 1.41 & 1.91 \\
\hline $100 \times 50 \times 4-\mathrm{C} 0-\mathrm{A}$ & 2.0 & 21.5 & 922 & 2.8 & 3.9 & 1.00 & 1.39 \\
$100 \times 50 \times 4-\mathrm{C} 40-\mathrm{A}$ & 2.0 & 21.5 & 1113 & 3.0 & 4.6 & 1.21 & 1.53 \\
$100 \times 50 \times 4-\mathrm{C} 40-\mathrm{A}-\mathrm{r}$ & 2.0 & 21.5 & 1112 & 5.1 & 6.0 & 1.21 & 1.18 \\
$100 \times 50 \times 4-\mathrm{C} 80-\mathrm{A}$ & 2.0 & 21.3 & 1211 & 4.0 & 6.0 & 1.31 & 1.50 \\
$100 \times 50 \times 4-\mathrm{C} 120-\mathrm{A}$ & 2.0 & 21.5 & 1198 & 3.4 & 5.1 & 1.30 & 1.50 \\
\hline $100 \times 100 \times 4-\mathrm{C} 0-\mathrm{A}$ & 1.0 & 21.0 & 1241 & 2.3 & 2.8 & 1.00 & 1.22 \\
$100 \times 100 \times 4-\mathrm{C} 40-\mathrm{A}$ & 1.0 & 21.0 & 1666 & 3.0 & $>4.7$ & 1.34 & $>1.57$ \\
$100 \times 100 \times 4-\mathrm{C} 80-\mathrm{A}$ & 1.0 & 21.3 & 1853 & 2.8 & 5.1 & 1.49 & 1.82 \\
$100 \times 100 \times 4-\mathrm{C} 120-\mathrm{A}$ & 1.0 & 21.3 & 1957 & 2.9 & $>8.2$ & 1.58 & $>2.83$ \\
\hline $140 \times 140 \times 5-\mathrm{C} 0-\mathrm{A}$ & 1.0 & 23.8 & 2033 & 2.6 & 3.2 & 1.00 & 1.23 \\
$140 \times 140 \times 5-\mathrm{C} 40-\mathrm{A}$ & 1.0 & 23.7 & 2992 & 5.2 & 15.1 & 1.47 & 2.90 \\
$140 \times 140 \times 5-\mathrm{C} 80-\mathrm{A}$ & 1.0 & 23.5 & 3237 & 4.3 & 13.3 & 1.59 & 3.09 \\
$140 \times 140 \times 5-\mathrm{C} 120-\mathrm{A}$ & 1.0 & 23.8 & 3760 & 2.6 & 5.0 & 1.85 & 1.92 \\
\hline $160 \times 160 \times 4-\mathrm{C} 0-\mathrm{A}$ & 1.0 & 35.0 & 1246 & 1.7 & 3.6 & 1.00 & 2.12 \\
$160 \times 160 \times 4-\mathrm{C} 40-\mathrm{A}$ & 1.0 & 35.2 & 2785 & 3.9 & $>6.4$ & 2.24 & $>1.64$ \\
$160 \times 160 \times 4-\mathrm{C} 80-\mathrm{A}$ & 1.0 & 35.3 & 3600 & 2.3 & 4.7 & 2.89 & 2.04 \\
$160 \times 160 \times 4-\mathrm{C} 120-\mathrm{A}$ & 1.0 & 35.1 & 4062 & 2.1 & 3.9 & 3.26 & 1.86 \\
\hline
\end{tabular}


Table 6: Test results of concrete-filled CFHSS stub columns using Series B steel tubes

\begin{tabular}{cccccccc}
\hline Specimens & $H / B$ & $h / t$ & $P_{t}(\mathrm{kN})$ & $\delta_{u}(\mathrm{~mm})$ & $\delta_{0.85 u}(\mathrm{~mm})$ & Nor. & $D I$ \\
\hline $80 \times 80 \times 4-C 0-B$ & 1.0 & 15.2 & 1431 & 3.3 & 3.8 & 1.00 & 1.15 \\
$80 \times 80 \times 4-C 40-B$ & 1.0 & 15.1 & 1722 & 3.4 & 4.6 & 1.20 & 1.35 \\
$80 \times 80 \times 4-C 80-B$ & 1.0 & 15.3 & 1791 & 3.7 & 7.5 & 1.25 & 2.03 \\
$80 \times 80 \times 4-C 120-B$ & 1.0 & 15.2 & 1898 & 3.4 & 5.9 & 1.33 & 1.74 \\
\hline $100 \times 100 \times 4-C 0-B$ & 1.0 & 19.6 & 1474 & 2.8 & 3.2 & 1.00 & 1.14 \\
$100 \times 100 \times 4-C 40-B$ & 1.0 & 19.7 & 2009 & 4.7 & 7.2 & 1.36 & 1.53 \\
$100 \times 100 \times 4-C 80-B$ & 1.0 & 19.9 & 2177 & 4.1 & 7.1 & 1.48 & 1.73 \\
$100 \times 100 \times 4-C 120-B$ & 1.0 & 19.7 & 2266 & 4.3 & $>9.3$ & 1.54 & $>2.16$ \\
\hline $120 \times 120 \times 4-C 0-B$ & 1.0 & 25.9 & 1400 & 1.9 & 3.3 & 1.00 & 1.74 \\
$120 \times 120 \times 4-C 40-B$ & 1.0 & 26.0 & 2557 & 4.1 & 5.5 & 1.83 & 1.34 \\
$120 \times 120 \times 4-C 80-B$ & 1.0 & 26.1 & 2853 & 4.2 & $>11.7$ & 2.04 & $>2.79$ \\
$120 \times 120 \times 4-C 80-B-r$ & 1.0 & 26.0 & 2798 & 3.3 & $>11.6$ & 2.00 & $>3.52$ \\
$120 \times 120 \times 4-C 120-B$ & 1.0 & 26.0 & 2950 & 2.9 & $>11.0$ & 2.11 & $>3.79$ \\
\hline
\end{tabular}

821 
Table 7: Comparison of test strengths with FE predictions

850

\begin{tabular}{|c|c|c|c|}
\hline Specimens & $P_{t}(\mathrm{kN})$ & $P_{F E A}(\mathrm{kN})$ & $P_{t} / P_{F E A}$ \\
\hline $80 \times 80 \times 4-\mathrm{C} 0-\mathrm{A}$ & 1064 & 1039 & 1.02 \\
\hline $80 \times 80 \times 4-C 40-A$ & 1328 & 1242 & 1.07 \\
\hline $80 \times 80 \times 4-C 80-A$ & 1462 & 1418 & 1.03 \\
\hline $80 \times 80 \times 4-C 120-A$ & 1504 & 1513 & 0.99 \\
\hline $100 \times 50 \times 4-\mathrm{C} 0-\mathrm{A}$ & 922 & 902 & 1.02 \\
\hline $100 \times 50 \times 4-C 40-A$ & 1113 & 1129 & 0.99 \\
\hline $100 \times 50 \times 4-C 80-A$ & 1211 & 1250 & 0.97 \\
\hline $100 \times 50 \times 4-C 120-A$ & 1193 & 1360 & 0.88 \\
\hline $100 \times 100 \times 4-\mathrm{C} 0-\mathrm{A}$ & 1241 & 1205 & 1.03 \\
\hline $100 \times 100 \times 4-C 40-A$ & 1666 & 1580 & 1.05 \\
\hline $100 \times 100 \times 4-C 80-A$ & 1853 & 1825 & 1.02 \\
\hline $100 \times 100 \times 4-\mathrm{C} 120-\mathrm{A}$ & 1957 & 2076 & 0.94 \\
\hline $140 \times 140 \times 5-\mathrm{C} 0-\mathrm{A}$ & 2033 & 2134 & 0.95 \\
\hline $140 \times 140 \times 5-C 40-A$ & 2992 & 3028 & 0.99 \\
\hline $140 \times 140 \times 5-C 80-A$ & 3237 & 3321 & 0.97 \\
\hline $140 \times 140 \times 5-\mathrm{C} 120-\mathrm{A}$ & 3760 & 3735 & 1.01 \\
\hline $160 \times 160 \times 4-\mathrm{C} 0-\mathrm{A}$ & 1246 & 1225 & 1.02 \\
\hline $160 \times 160 \times 4-C 40-A$ & 2785 & 2257 & 1.23 \\
\hline $160 \times 160 \times 4-C 80-A$ & 3600 & 3198 & 1.13 \\
\hline $160 \times 160 \times 4-\mathrm{C} 120-\mathrm{A}$ & 4062 & 4226 & 0.96 \\
\hline $80 \times 80 \times 4-\mathrm{C} 0-\mathrm{B}$ & 1431 & 1377 & 1.04 \\
\hline $80 \times 80 \times 4-C 40-B$ & 1722 & 1637 & 1.05 \\
\hline $80 \times 80 \times 4-C 80-B$ & 1791 & 1728 & 1.04 \\
\hline $80 \times 80 \times 4-C 120-B$ & 1898 & 1797 & 1.06 \\
\hline $100 \times 100 \times 4-C 0-B$ & 1474 & 1639 & 0.90 \\
\hline $100 \times 100 \times 4-C 40-B$ & 2009 & 2006 & 1.00 \\
\hline $100 \times 100 \times 4-C 80-B$ & 2177 & 2214 & 0.98 \\
\hline $100 \times 100 \times 4-\mathrm{C} 120-\mathrm{B}$ & 2266 & 2387 & 0.95 \\
\hline $120 \times 120 \times 4-\mathrm{C} 0-\mathrm{B}$ & 1400 & 1874 & 0.75 \\
\hline $120 \times 120 \times 4-C 40-B$ & 2557 & 2606 & 0.98 \\
\hline $120 \times 120 \times 4-C 80-B$ & 2853 & 2864 & 1.00 \\
\hline \multirow[t]{3}{*}{$120 \times 120 \times 4-\mathrm{C} 120-\mathrm{B}$} & 2950 & 3085 & 0.96 \\
\hline & & Mean & 1.00 \\
\hline & & $\mathrm{COV}$ & 0.079 \\
\hline
\end{tabular}


Table 8: Dimensions and results of concrete-filled CFHSS square stub columns in parametric study

869

\begin{tabular}{ccccccc}
\hline Specimens & $h / t$ & $P_{F E A}(\mathrm{kN})$ & $\delta_{u}(\mathrm{~mm})$ & $\delta_{0.85 u}(\mathrm{~mm})$ & Nor. & $D I$ \\
\hline $45 \times 45 \times 3-\mathrm{C} 0-\mathrm{A}$ & 10.0 & 408 & 1.93 & 2.88 & 1.00 & 1.49 \\
$45 \times 45 \times 3-\mathrm{C} 40-\mathrm{A}$ & & 499 & 8.62 & - & 1.22 & \\
$45 \times 45 \times 3-\mathrm{C} 80-\mathrm{A}$ & & 529 & 4.31 & 13.36 & 1.30 & 3.10 \\
$45 \times 45 \times 3-\mathrm{C} 120-\mathrm{A}$ & & 567 & 5.05 & 8.98 & 1.39 & 1.78 \\
\hline $250 \times 250 \times 5-\mathrm{C} 0-\mathrm{A}$ & 45.0 & 2310 & 3.75 & 8.55 & 1.00 & 2.28 \\
$250 \times 250 \times 5-\mathrm{C} 40-\mathrm{A}$ & & 4603 & 1.88 & 4.07 & 1.99 & 2.16 \\
$250 \times 250 \times 5-\mathrm{C} 80-\mathrm{A}$ & & 7050 & 2.05 & 2.69 & 3.05 & 1.31 \\
$250 \times 250 \times 5-\mathrm{C} 120-\mathrm{A}$ & & 9650 & 2.45 & 2.93 & 4.18 & 1.20 \\
\hline $360 \times 360 \times 6-\mathrm{C} 0-\mathrm{A}$ & 55.0 & 4543 & 3.33 & 10.63 & 1.00 & 3.19 \\
$360 \times 360 \times 6-\mathrm{C} 40-\mathrm{A}$ & & 8690 & 2.67 & 4.42 & 1.91 & 1.66 \\
$360 \times 360 \times 6-\mathrm{C} 80-\mathrm{A}$ & & 13994 & 2.96 & 3.64 & 3.08 & 1.23 \\
$360 \times 360 \times 6-\mathrm{C} 120-\mathrm{A}$ & & 19071 & 3.32 & 4.10 & 4.20 & 1.23 \\
\hline $45 \times 45 \times 3-\mathrm{C} 0-\mathrm{B}$ & 10.0 & 545 & 1.55 & 1.96 & 1.00 & 1.26 \\
$45 \times 45 \times 3-\mathrm{C} 40-\mathrm{B}$ & & 641 & 1.93 & - & 1.18 & \\
$45 \times 45 \times 3-\mathrm{C} 80-\mathrm{B}$ & & 663 & 2.00 & 2.91 & 1.22 & 1.46 \\
$45 \times 45 \times 3-\mathrm{C} 120-\mathrm{B}$ & & 682 & 1.77 & 2.85 & 1.25 & 1.61 \\
\hline $160 \times 160 \times 4-\mathrm{C} 0-\mathrm{B}$ & 35.0 & 1437 & 2.34 & 4.26 & 1.00 & 1.82 \\
$160 \times 160 \times 4-\mathrm{C} 40-\mathrm{B}$ & & 2182 & 1.83 & 2.06 & 1.52 & 1.13 \\
$160 \times 160 \times 4-\mathrm{C} 80-\mathrm{B}$ & & 3428 & 1.59 & 2.97 & 2.39 & 1.87 \\
$160 \times 160 \times 4-\mathrm{C} 120-\mathrm{B}$ & & 4460 & 1.76 & 2.42 & 3.10 & 1.38 \\
\hline $250 \times 250 \times 5-\mathrm{C} 0-\mathrm{B}$ & 45.0 & 2718 & 4.80 & 7.89 & 1.00 & 1.64 \\
$250 \times 250 \times 5-\mathrm{C} 40-\mathrm{B}$ & & 5089 & 4.01 & 7.12 & 1.87 & 1.78 \\
$250 \times 250 \times 5-\mathrm{C} 80-\mathrm{B}$ & & 7410 & 2.34 & 3.62 & 2.73 & 1.55 \\
$250 \times 250 \times 5-\mathrm{C} 120-\mathrm{B}$ & & 10125 & 2.59 & 3.22 & 3.73 & 1.24 \\
\hline $360 \times 360 \times 6-\mathrm{C} 0-\mathrm{B}$ & 55.0 & 5093 & 3.42 & 3.56 & 1.00 & 1.04 \\
$360 \times 360 \times 6-\mathrm{C} 40-\mathrm{B}$ & & 8996 & 2.74 & 10.74 & 1.77 & 3.92 \\
$360 \times 360 \times 6-\mathrm{C} 80-\mathrm{B}$ & & 14406 & 3.09 & 4.03 & 2.83 & 1.30 \\
$360 \times 360 \times 6-\mathrm{C} 120-\mathrm{B}$ & & 19615 & 3.20 & 3.89 & 3.85 & 1.22 \\
\hline $50 \% 5$
\end{tabular}


Table 9: Dimensions and results of concrete-filled CFHSS rectangular stub columns in parametric study

\begin{tabular}{ccccccc}
\hline Specimens & $h / t$ & $P_{F E A}(\mathrm{kN})$ & $\delta_{u}(\mathrm{~mm})$ & $\delta_{0.85 u}(\mathrm{~mm})$ & Nor. & $D I$ \\
\hline $120 \times 60 \times 3-\mathrm{C} 0-\mathrm{A}$ & 35.0 & 659 & 1.82 & 3.64 & 1.00 & 2.00 \\
$120 \times 60 \times 3-\mathrm{C} 40-\mathrm{A}$ & & 912 & 1.98 & 3.99 & 1.38 & 2.02 \\
$120 \times 60 \times 3-\mathrm{C} 80-\mathrm{A}$ & & 1096 & 1.23 & 2.25 & 1.66 & 1.83 \\
$120 \times 60 \times 3-\mathrm{C} 120-\mathrm{A}$ & & 1382 & 1.30 & 1.54 & 2.10 & 1.18 \\
\hline $180 \times 90 \times 3-\mathrm{C} 0-\mathrm{A}$ & 55.0 & 759 & 2.23 & 4.10 & 1.00 & 1.84 \\
$180 \times 90 \times 3-\mathrm{C} 40-\mathrm{A}$ & & 1550 & 1.46 & 2.90 & 2.04 & 1.99 \\
$180 \times 90 \times 3-\mathrm{C} 80-\mathrm{A}$ & & 2044 & 1.72 & 1.94 & 2.69 & 1.13 \\
$180 \times 90 \times 3-\mathrm{C} 120-\mathrm{A}$ & & 2673 & 1.95 & 2.17 & 3.52 & 1.11 \\
\hline $320 \times 160 \times 4-\mathrm{C} 0-\mathrm{A}$ & 75.0 & 1829 & 5.53 & 11.64 & 1.00 & 2.10 \\
$320 \times 160 \times 4-\mathrm{C} 40-\mathrm{A}$ & & 3595 & 2.55 & 2.83 & 1.97 & 1.11 \\
$320 \times 160 \times 4-\mathrm{C} 80-\mathrm{A}$ & & 5619 & 2.91 & 3.18 & 3.07 & 1.09 \\
$320 \times 160 \times 4-\mathrm{C} 120-\mathrm{A}$ & & 7586 & 3.10 & 4.24 & 4.15 & 1.37 \\
\hline $120 \times 60 \times 3-\mathrm{C} 0-\mathrm{B}$ & 35.0 & 807 & 2.46 & 3.33 & 1.00 & 1.35 \\
$120 \times 60 \times 3-\mathrm{C} 40-\mathrm{B}$ & & 1128 & 2.38 & 3.37 & 1.40 & 1.42 \\
$120 \times 60 \times 3-\mathrm{C} 80-\mathrm{B}$ & & 1232 & 2.08 & 3.14 & 1.53 & 1.51 \\
$120 \times 60 \times 3-\mathrm{C} 120-\mathrm{B}$ & & 1468 & 1.33 & 2.33 & 1.82 & 1.75 \\
\hline $180 \times 90 \times 3-\mathrm{C} 0-\mathrm{B}$ & 55.0 & 920 & 2.99 & 4.19 & 1.00 & 1.40 \\
$180 \times 90 \times 3-\mathrm{C} 40-\mathrm{B}$ & & 1543 & 1.74 & 3.41 & 1.68 & 1.96 \\
$180 \times 90 \times 3-\mathrm{C} 80-\mathrm{B}$ & & 2182 & 1.83 & 2.06 & 2.37 & 1.13 \\
$180 \times 90 \times 3-\mathrm{C} 120-\mathrm{B}$ & & 2781 & 1.98 & 2.23 & 3.02 & 1.13 \\
\hline $320 \times 160 \times 4-\mathrm{C} 0-\mathrm{B}$ & 75.0 & 2142 & 6.41 & 9.83 & 1.00 & 1.53 \\
$320 \times 160 \times 4-\mathrm{C} 40-\mathrm{B}$ & & 3778 & 2.65 & 6.47 & 1.76 & 2.44 \\
$320 \times 160 \times 4-\mathrm{C} 80-\mathrm{B}$ & & 5805 & 2.94 & 3.25 & 2.71 & 1.11 \\
$320 \times 160 \times 4-\mathrm{C} 120-\mathrm{B}$ & & 7652 & 3.34 & 3.69 & 3.57 & 1.10 \\
\hline “ & & & & & & \\
\hline
\end{tabular}


Table 10: Comparison of test and FE results with predictions from EC4 [22]

\begin{tabular}{|c|c|c|c|c|c|c|c|}
\hline Specimens & No. & & & $P P_{u} / P_{E C}$ & $\overline{P_{u} / P_{E C^{*}}}$ & $\bar{P} P_{u} / P_{E C^{\wedge}}$ & $\overline{P_{u} / P_{E C^{* \wedge}}}$ \\
\hline \multirow{3}{*}{ Square specimens } & 21 & Series A & $\begin{array}{l}\text { Mean } \\
\text { COV }\end{array}$ & $\begin{array}{c}1.03 \\
0.137\end{array}$ & $\begin{array}{c}1.10 \\
0.096\end{array}$ & $\begin{array}{c}1.09 \\
0.115\end{array}$ & $\begin{array}{c}1.18 \\
0.074\end{array}$ \\
\hline & 22 & Series B & $\begin{array}{l}\text { Mean } \\
\text { COV }\end{array}$ & $\begin{array}{c}0.95 \\
0.180 \\
\end{array}$ & $\begin{array}{c}1.08 \\
0.097 \\
\end{array}$ & $\begin{array}{c}1.01 \\
0.167 \\
\end{array}$ & $\begin{array}{c}1.15 \\
0.091 \\
\end{array}$ \\
\hline & 43 & Series A\&B & $\begin{array}{l}\text { Mean } \\
\text { COV }\end{array}$ & $\begin{array}{c}0.99 \\
0.162\end{array}$ & $\begin{array}{c}1.09 \\
0.096\end{array}$ & $\begin{array}{c}1.05 \\
0.147\end{array}$ & $\begin{array}{c}1.17 \\
0.083\end{array}$ \\
\hline \multirow{3}{*}{ Rectangular specimens } & 13 & Series A & $\begin{array}{l}\text { Mean } \\
\text { COV }\end{array}$ & $\begin{array}{c}0.96 \\
0.127\end{array}$ & $\begin{array}{c}1.09 \\
0.064\end{array}$ & $\begin{array}{c}1.02 \\
0.115\end{array}$ & $\begin{array}{c}1.16 \\
0.063\end{array}$ \\
\hline & 9 & Series B & $\begin{array}{l}\text { Mean } \\
\text { COV }\end{array}$ & $\begin{array}{c}0.81 \\
0.084\end{array}$ & $\begin{array}{c}1.05 \\
0.041\end{array}$ & $\begin{array}{c}0.86 \\
0.109\end{array}$ & $\begin{array}{c}1.13 \\
0.065\end{array}$ \\
\hline & 22 & Series A\&B & $\begin{array}{l}\text { Mean } \\
\text { COV }\end{array}$ & $\begin{array}{c}0.90 \\
0.141\end{array}$ & $\begin{array}{c}1.07 \\
0.059\end{array}$ & $\begin{array}{c}0.95 \\
0.138\end{array}$ & $\begin{array}{c}1.15 \\
0.064\end{array}$ \\
\hline
\end{tabular}

Table 11: Comparison of test and FE results with predictions from AISC [23]

\begin{tabular}{|c|c|c|c|c|c|}
\hline Specimens & No. & & & $P_{u} / P_{A I S C}$ & $P_{u} / P_{A I S C^{\wedge}}$ \\
\hline \multirow{3}{*}{ Square specimens } & 21 & Series A & $\begin{array}{l}\text { Mean } \\
\text { COV }\end{array}$ & $\begin{array}{c}1.12 \\
0.101\end{array}$ & $\begin{array}{c}1.19 \\
0.097\end{array}$ \\
\hline & 22 & Series B & $\begin{array}{l}\text { Mean } \\
\text { COV }\end{array}$ & $\begin{array}{c}1.07 \\
0.140\end{array}$ & $\begin{array}{c}1.12 \\
0.147\end{array}$ \\
\hline & 43 & Series A\&B & $\begin{array}{l}\text { Mean } \\
\text { COV }\end{array}$ & $\begin{array}{c}1.09 \\
0.123 \\
\end{array}$ & $\begin{array}{c}1.16 \\
0.126 \\
\end{array}$ \\
\hline \multirow{5}{*}{ Rectangular specimens } & \multirow[t]{2}{*}{13} & \multirow[t]{2}{*}{ Series A } & Mean & 1.17 & 1.24 \\
\hline & & & $\mathrm{COV}$ & 0.142 & 0.173 \\
\hline & \multirow[t]{2}{*}{9} & \multirow[t]{2}{*}{ Series B } & Mean & $1.20(1.30)^{*}$ & $1.29(1.41)^{*}$ \\
\hline & & & $\mathrm{COV}$ & $0.209(0.300)^{*}$ & $0.242(0.325)^{*}$ \\
\hline & 22 & Series A\&B & $\begin{array}{l}\text { Mean } \\
\text { COV }\end{array}$ & $\begin{array}{c}1.18(1.22)^{*} \\
0.170(0.228)^{*}\end{array}$ & $\begin{array}{c}1.26(1.31)^{*} \\
0.200(0.256)^{*}\end{array}$ \\
\hline
\end{tabular}

Note: "(x)*" = modified predicted strength incorporating effective area of steel tube; $P_{A I S C^{\wedge}}=$ modified predicted strength incorporating the effective compressive strength of concrete 
Table 12: Comparison of test and FE results with codified predictions for specimens with different infilled concrete compressive strengths

(a) Square specimens

\begin{tabular}{|c|c|c|c|c|c|c|c|c|}
\hline Cases & & $\begin{array}{c}\text { No. of } \\
\text { columns }\end{array}$ & $P_{u} / P_{E C}$ & $P_{u} / P_{E C^{*}}$ & $P_{u} / P_{E C^{\wedge}}$ & $P_{u} / P_{E C^{* \wedge}}$ & $P_{u} / P_{A I S C}$ & $P_{u} / P_{A I S C^{\wedge}}$ \\
\hline \multirow{2}{*}{ Infilled concrete $\mathrm{C} 40$} & Mean & \multirow{2}{*}{14} & 1.04 & 1.17 & 1.04 & 1.17 & 1.12 & 1.12 \\
\hline & $\mathrm{COV}$ & & 0.232 & 0.120 & 0.232 & 0.120 & 0.176 & 0.176 \\
\hline \multirow{2}{*}{ Infilled concrete $\mathrm{C} 80$} & Mean & \multirow{2}{*}{15} & 0.97 & 1.07 & 1.05 & 1.16 & 1.08 & 1.15 \\
\hline & $\mathrm{COV}$ & & 0.121 & 0.050 & 0.109 & 0.051 & 0.088 & 0.087 \\
\hline \multirow{2}{*}{ Infilled concrete $\mathrm{C} 120$} & Mean & \multirow{2}{*}{14} & 0.96 & 1.03 & 1.06 & 1.16 & 1.08 & 1.20 \\
\hline & $\mathrm{COV}$ & & 0.076 & 0.046 & 0.060 & 0.072 & 0.086 & 0.102 \\
\hline \multirow{2}{*}{ All cases } & Mean & \multirow{2}{*}{43} & 0.99 & 1.09 & 1.05 & 1.17 & 1.09 & 1.16 \\
\hline & $\mathrm{COV}$ & & 0.162 & 0.096 & 0.147 & 0.083 & 0.123 & 0.126 \\
\hline
\end{tabular}

Note: $P_{E C^{*}}=$ modified predicted strength incorporating effective area of steel tube; $P_{E C^{\wedge}}=$ modified predicted strength incorporating the effective compressive strength of concrete; and $P_{E C^{* \wedge}}=$ modified predicted strength incorporating both the effective area of steel tube and effective compressive strength of concrete; $P_{A I S C^{\wedge}}=$ modified predicted strength incorporating the effective compressive strength of concrete.

(b) Rectangular specimens

\begin{tabular}{|c|c|c|c|c|c|c|c|c|}
\hline Cases & & $\begin{array}{c}\text { No. of } \\
\text { columns }\end{array}$ & $P_{u} / P_{E C}$ & $P_{u} / P_{E C^{*}}$ & $P_{u} / P_{E C^{\wedge}}$ & $P_{u} / P_{E C^{* \wedge}}$ & $P_{u} / P_{A I S C}$ & $P_{u} / P_{A I S C^{\wedge}}$ \\
\hline \multirow{2}{*}{ Infilled concrete $\mathrm{C} 40$} & Mean & \multirow{2}{*}{ 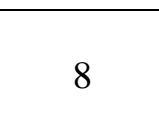 } & 0.92 & 1.12 & 0.92 & 1.12 & $1.18(1.24)^{*}$ & $1.18(1.24)^{*}$ \\
\hline & $\mathrm{COV}$ & & 0.211 & 0.054 & 0.211 & 0.054 & $0.157(0.256)^{*}$ & $0.157(0.256)^{*}$ \\
\hline \multirow{2}{*}{ Infilled concrete $\mathrm{C} 80$} & Mean & \multirow{2}{*}{7} & 0.88 & 1.05 & 0.94 & 1.14 & $1.18(1.21)^{*}$ & $1.27(1.32)^{*}$ \\
\hline & $\mathrm{COV}$ & & 0.106 & 0.038 & 0.101 & 0.056 & $0.195(0.245)^{*}$ & $0.220(0.281)^{*}$ \\
\hline \multirow{2}{*}{ Infilled concrete $\mathrm{C} 120$} & Mean & \multirow{2}{*}{7} & 0.89 & 1.03 & 1.00 & 1.18 & $1.19(1.21)^{*}$ & $1.35(1.38)^{*}$ \\
\hline & $\mathrm{COV}$ & & 0.061 & 0.043 & 0.060 & 0.076 & $0.183(0.211)^{*}$ & $0.221(0.258)^{*}$ \\
\hline \multirow{2}{*}{ All cases } & Mean & \multirow{2}{*}{22} & 0.90 & 1.07 & 0.95 & 1.15 & $1.18(1.22)^{*}$ & $1.26(1.31)^{*}$ \\
\hline & $\mathrm{COV}$ & & 0.141 & 0.059 & 0.138 & 0.064 & $0.170(0.228)^{*}$ & $0.200(0.256)^{*}$ \\
\hline
\end{tabular}

Note: “ $(\mathrm{x})^{* \text { *” }}$ result by using reduced cross section area of steel tube. 


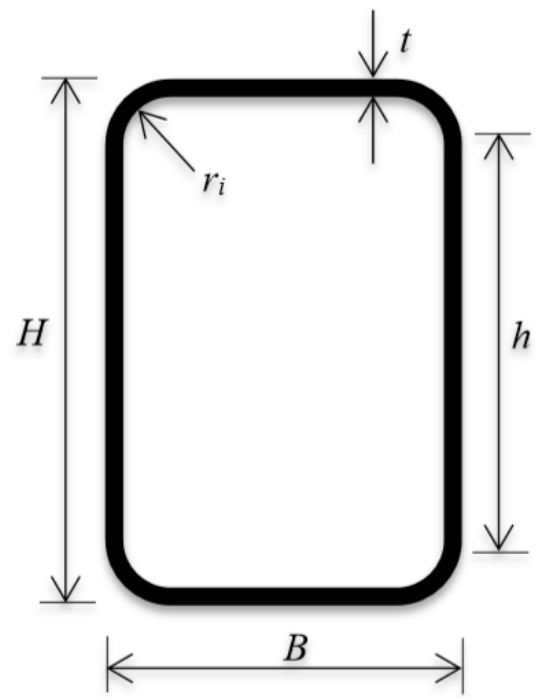

Figure 1: Symbols of CFHSS cross section 


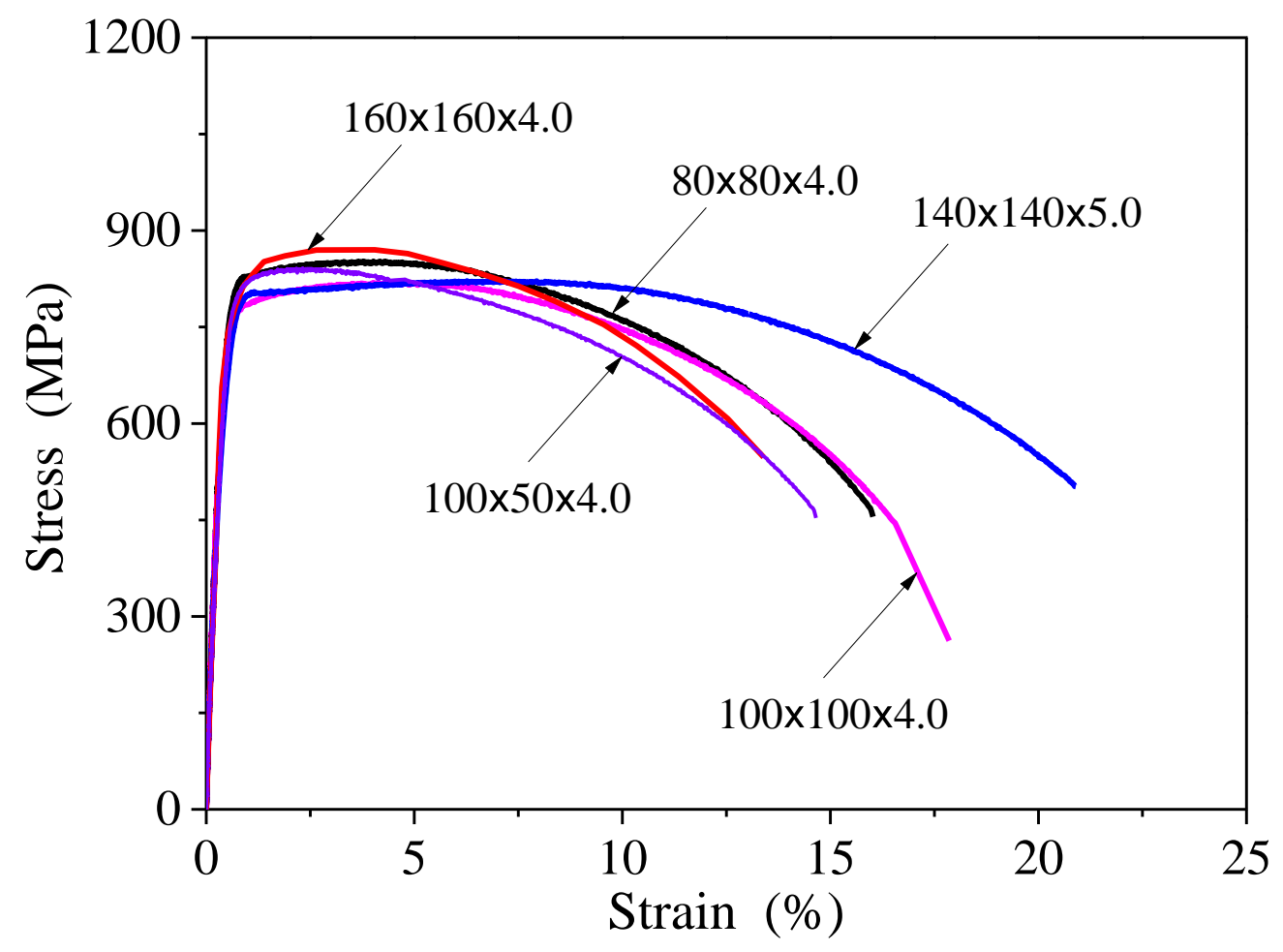

a) Members with nominal $0.2 . \%$ proof stress of $700 \mathrm{MPa}$

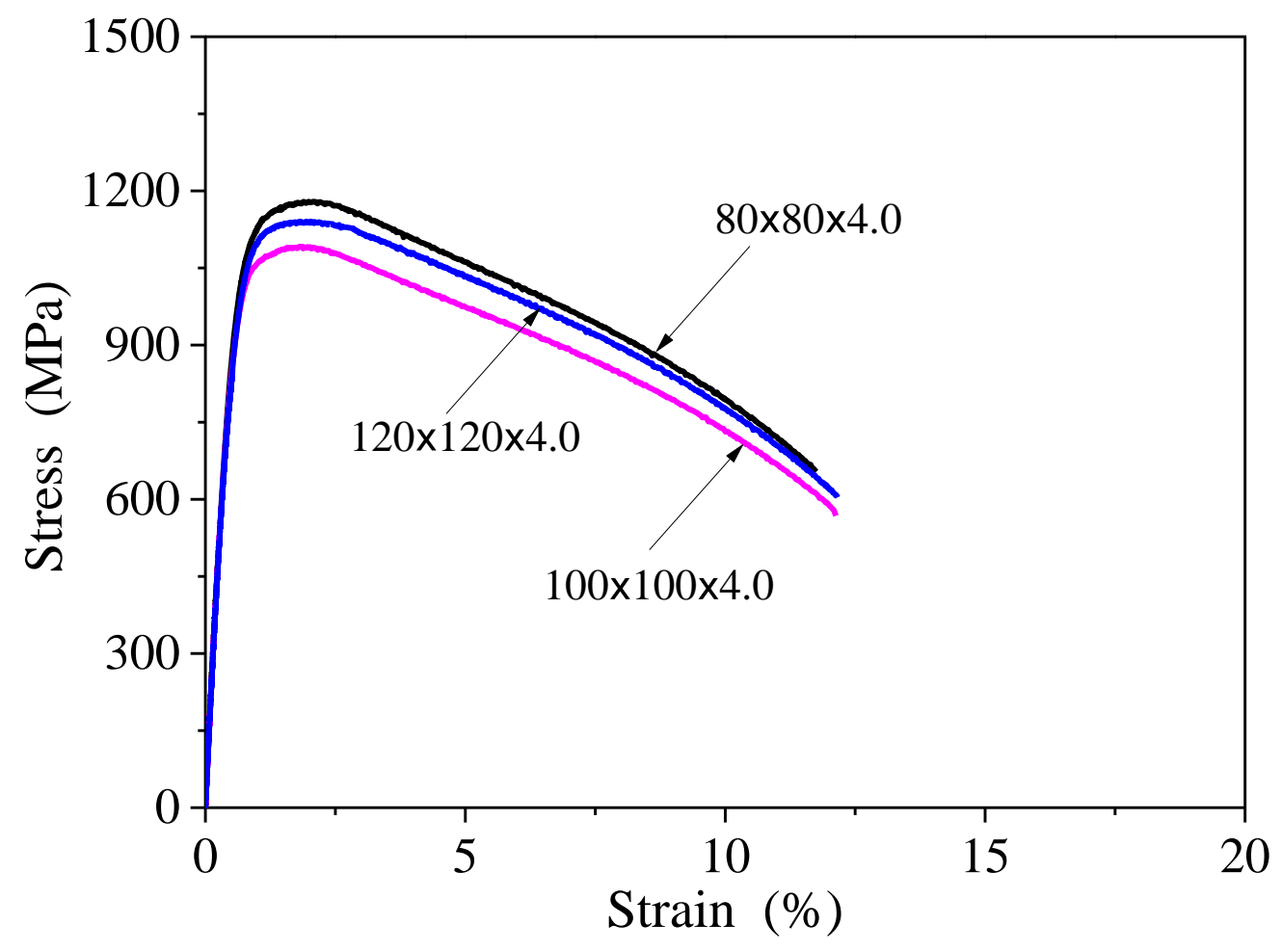

b) Members with nominal $0.2 . \%$ proof stress of $900 \mathrm{MPa}$

Figure 2: Measured stress-strain curves of high strength steel tubular members 


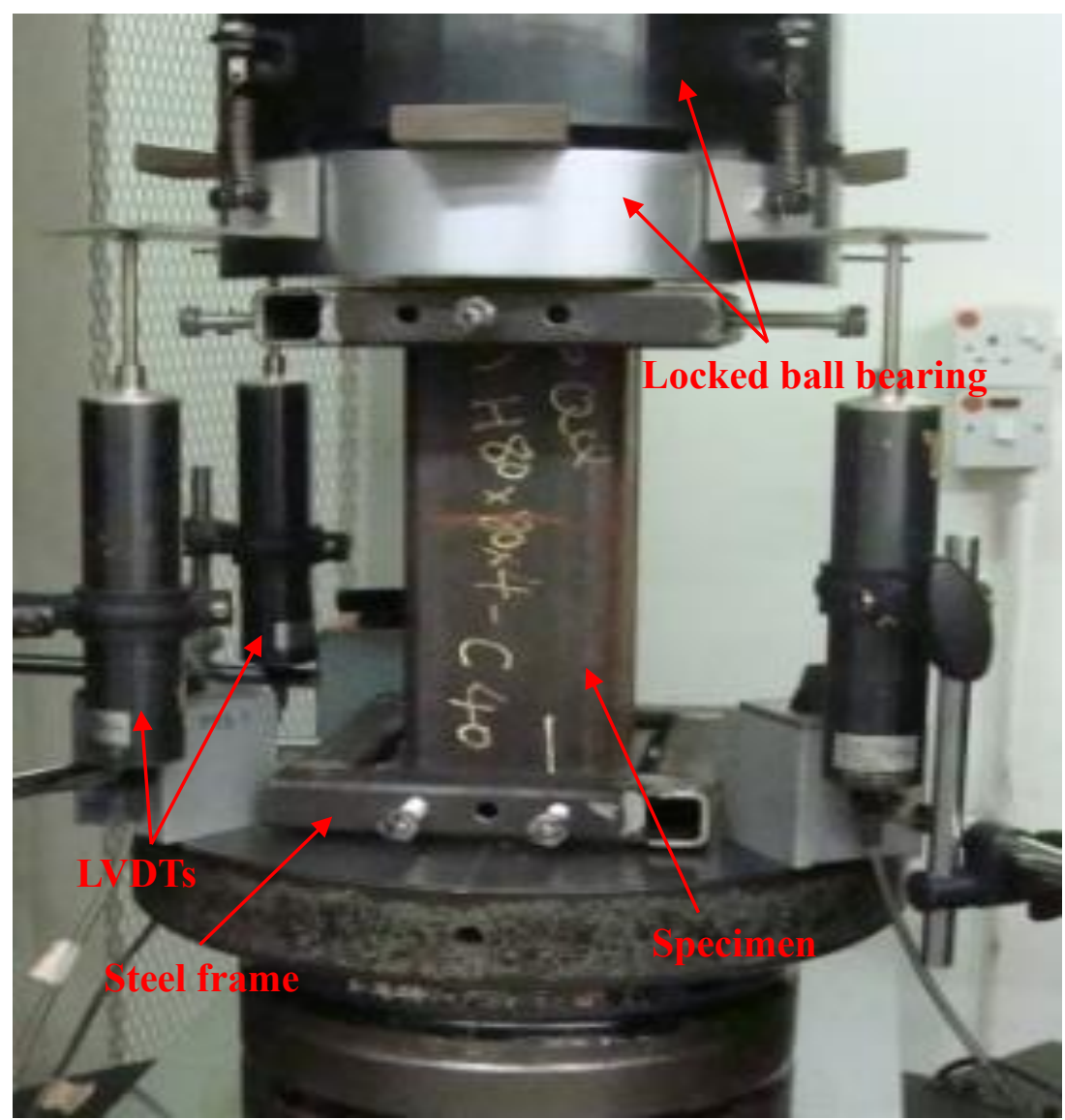

Figure 3: Test setup of concrete-filled stub column Specimen $80 \times 80 \times 4-\mathrm{C} 40-\mathrm{A}$

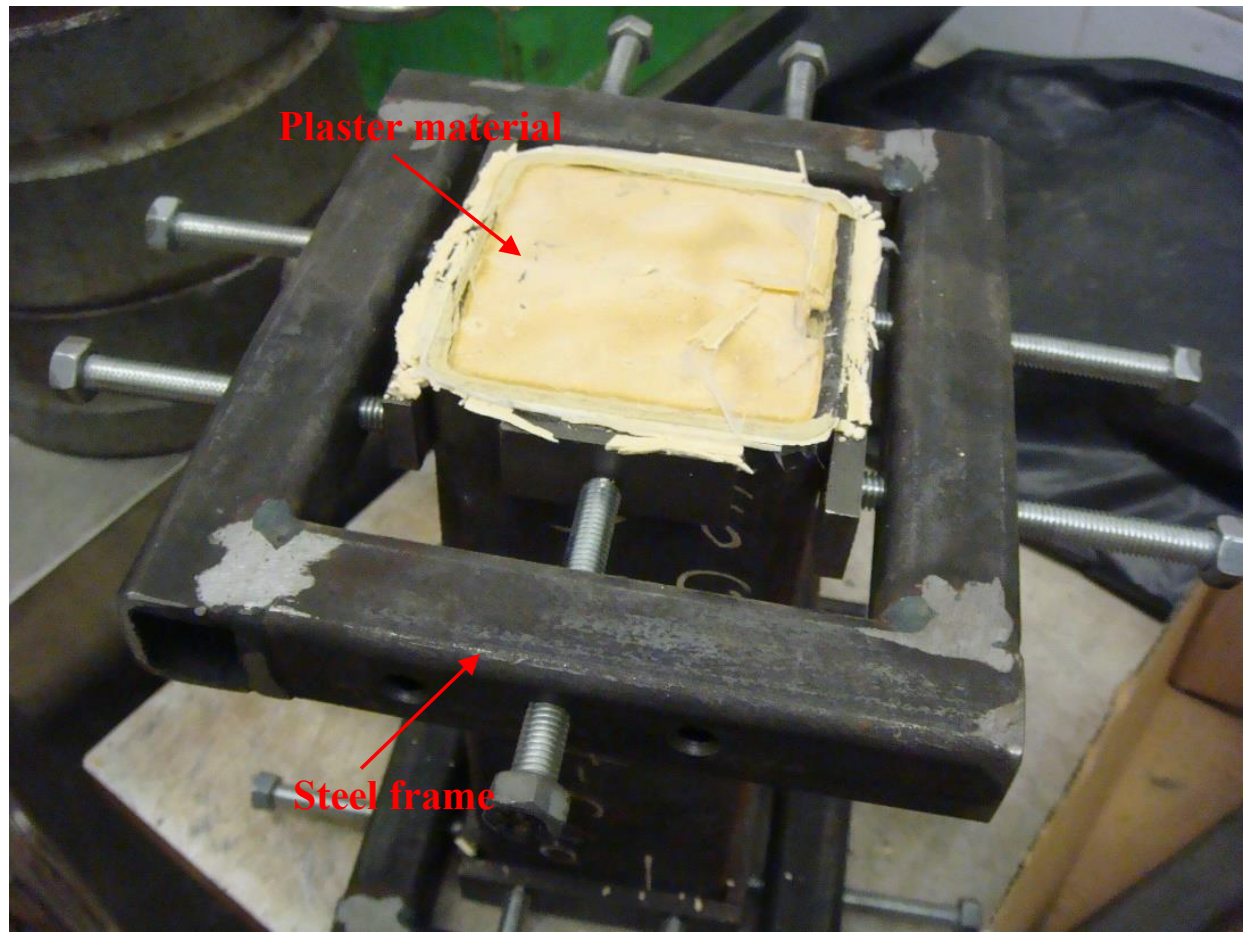

Figure 4: Specimen $80 \times 80 \times 4-\mathrm{C} 40-\mathrm{A}$ after compressive test 


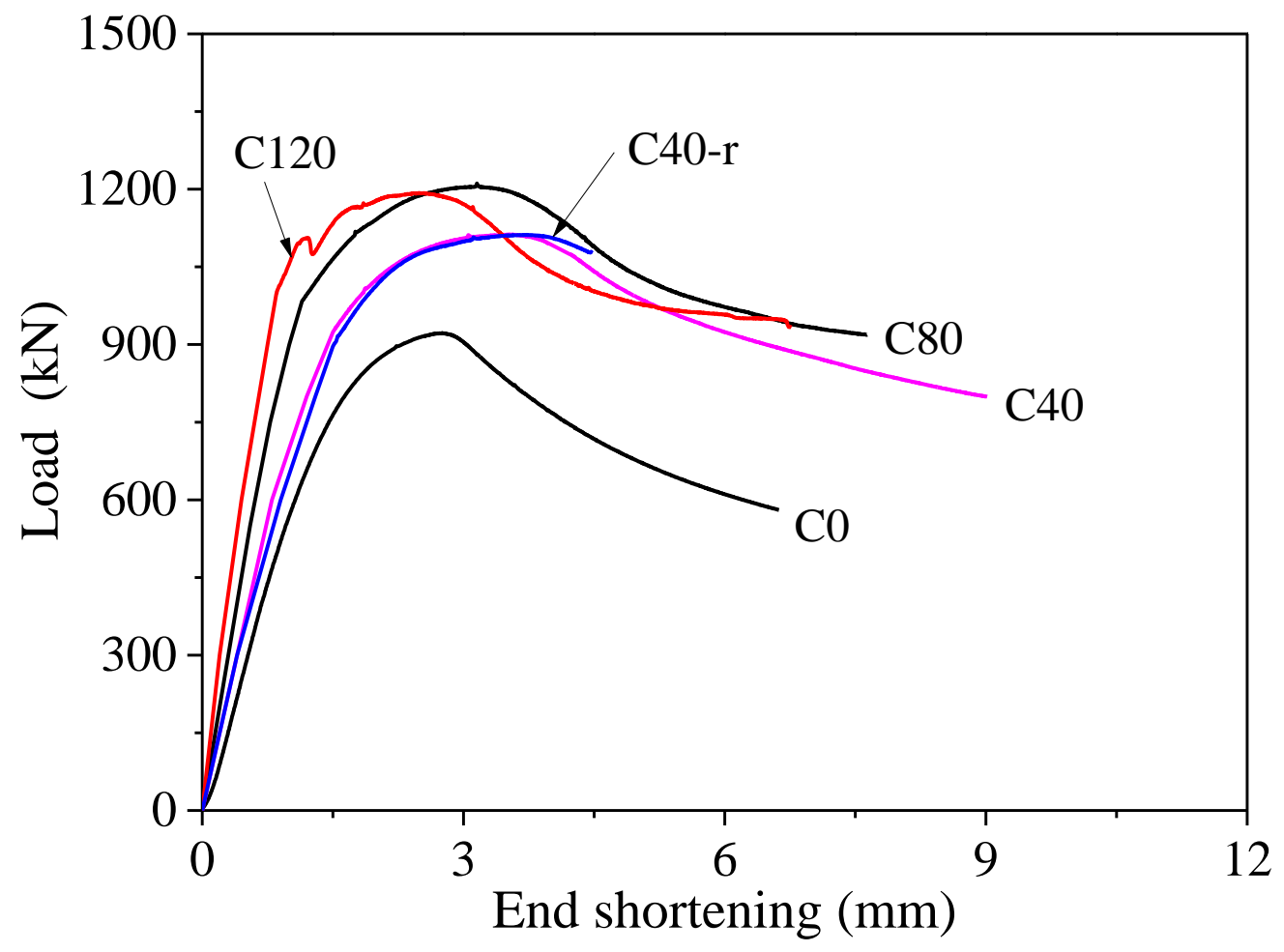

(a) Series $100 \times 50 \times 4-\mathrm{A}$

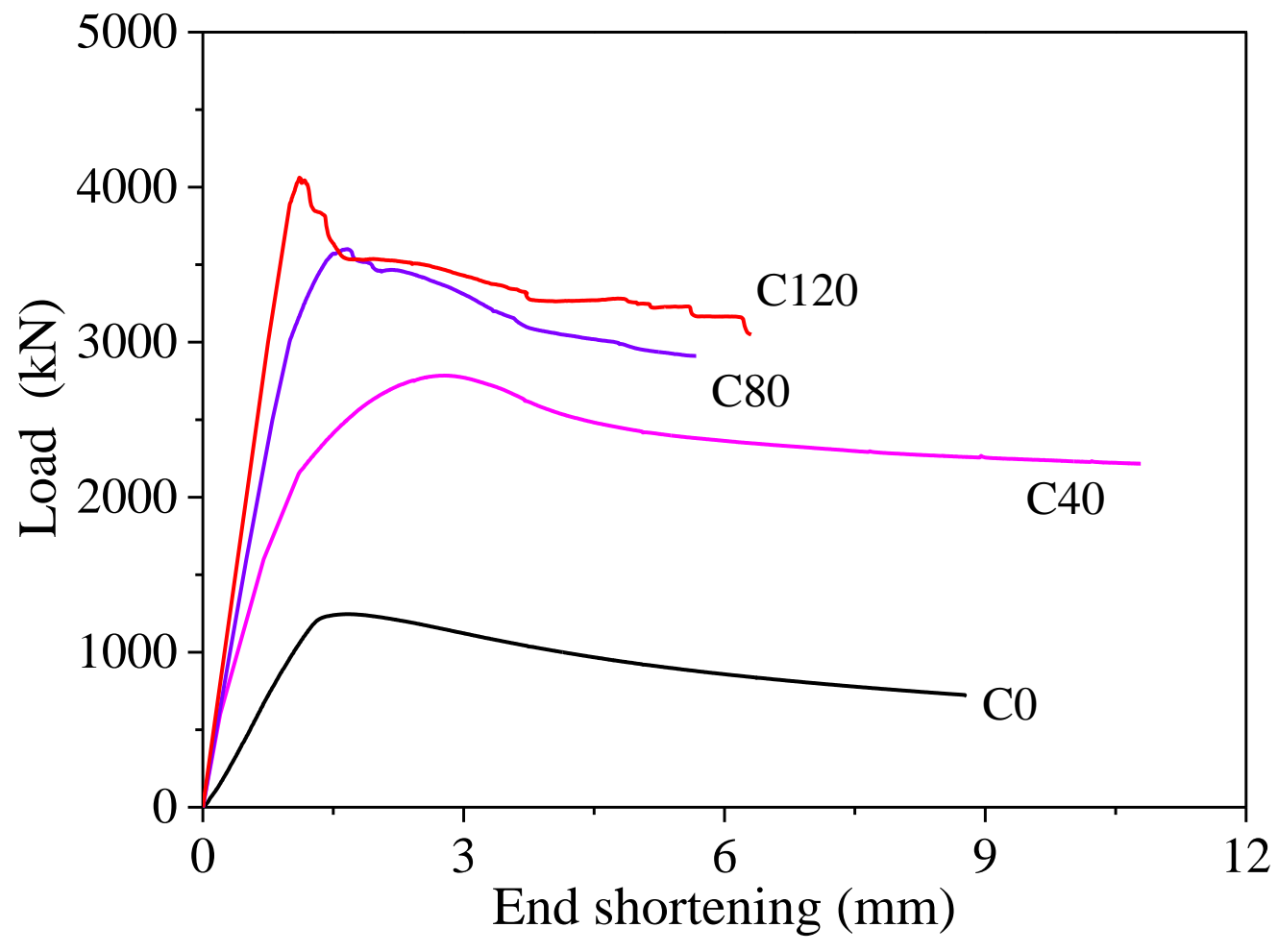

(b) Series $160 \times 160 \times 4-\mathrm{A}$ 


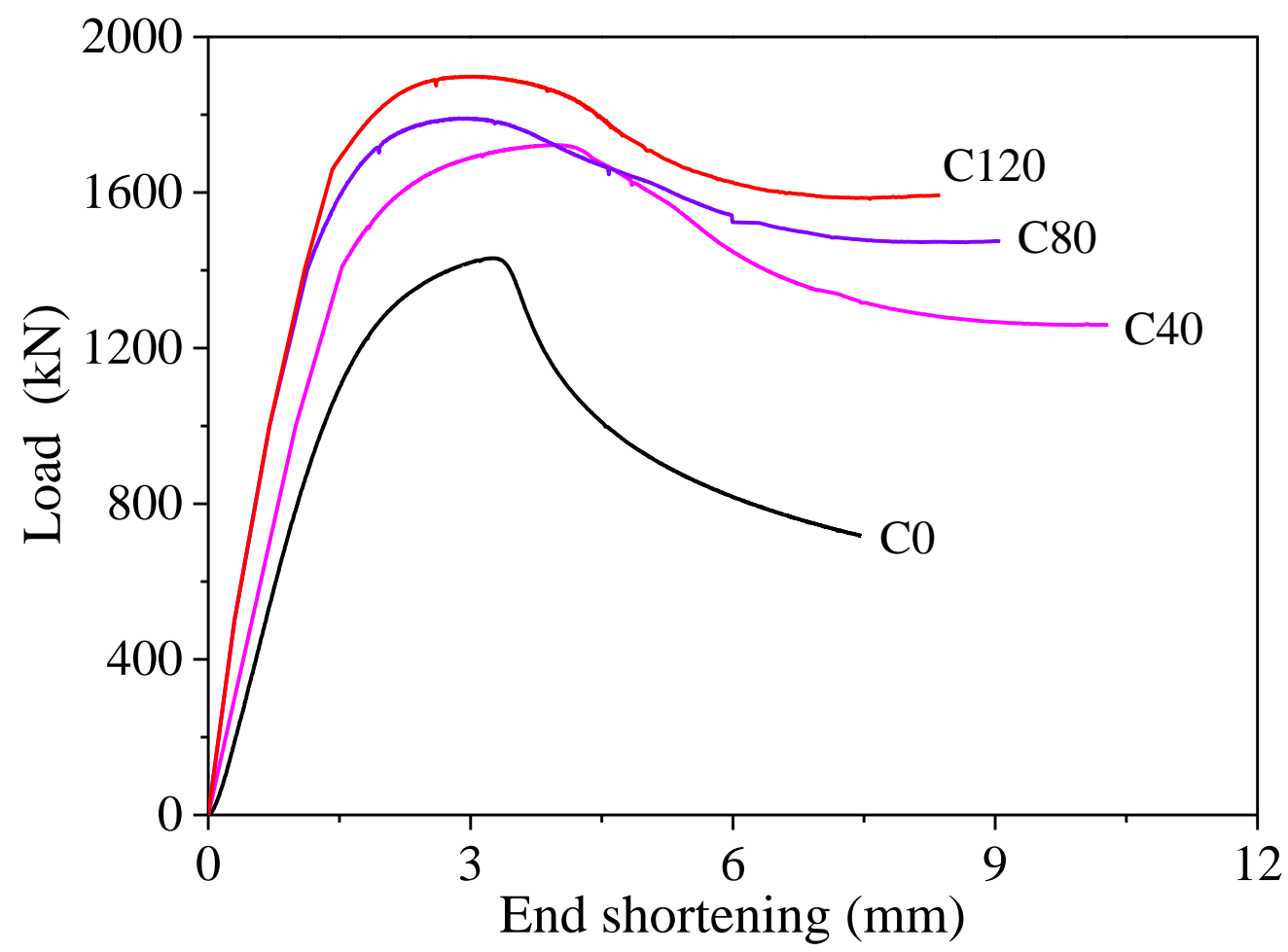

(c) Series $80 \times 80 \times 4$-B

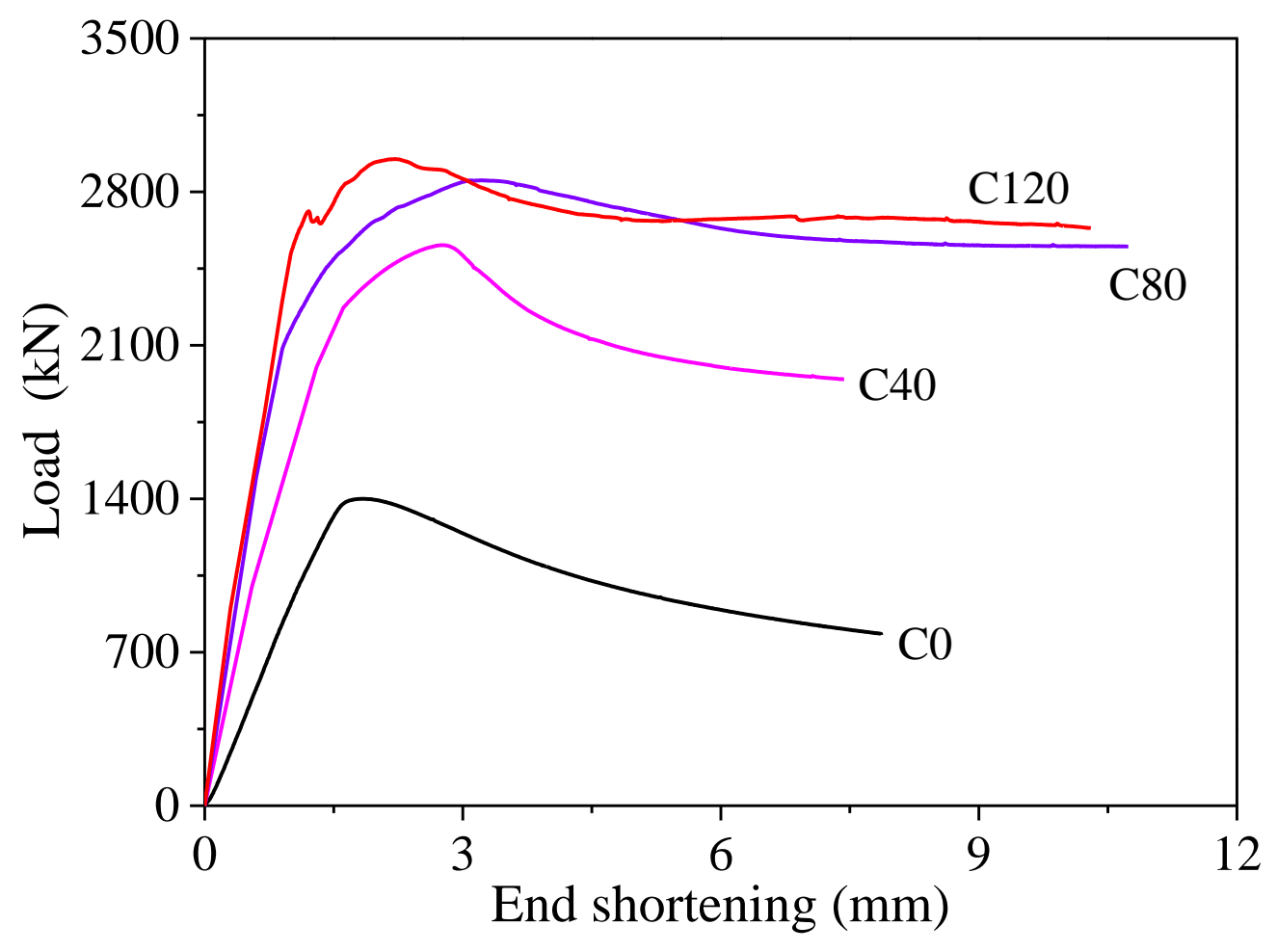

(d) Series $120 \times 120 \times 4-B$

Figure 5: Load-end shortening curves of concrete-filled CFHSS stub columns 


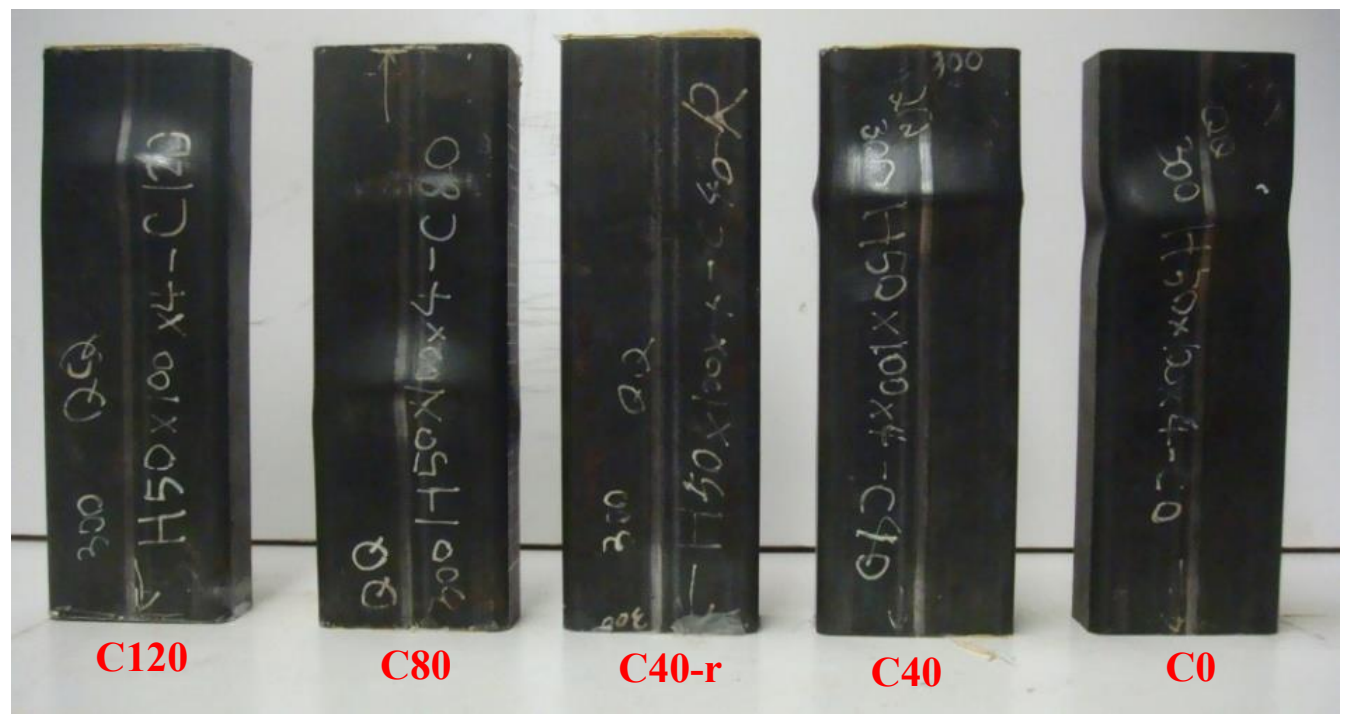

Figure 6: Failure modes of stub columns (series $100 \times 50 \times 4-A)$

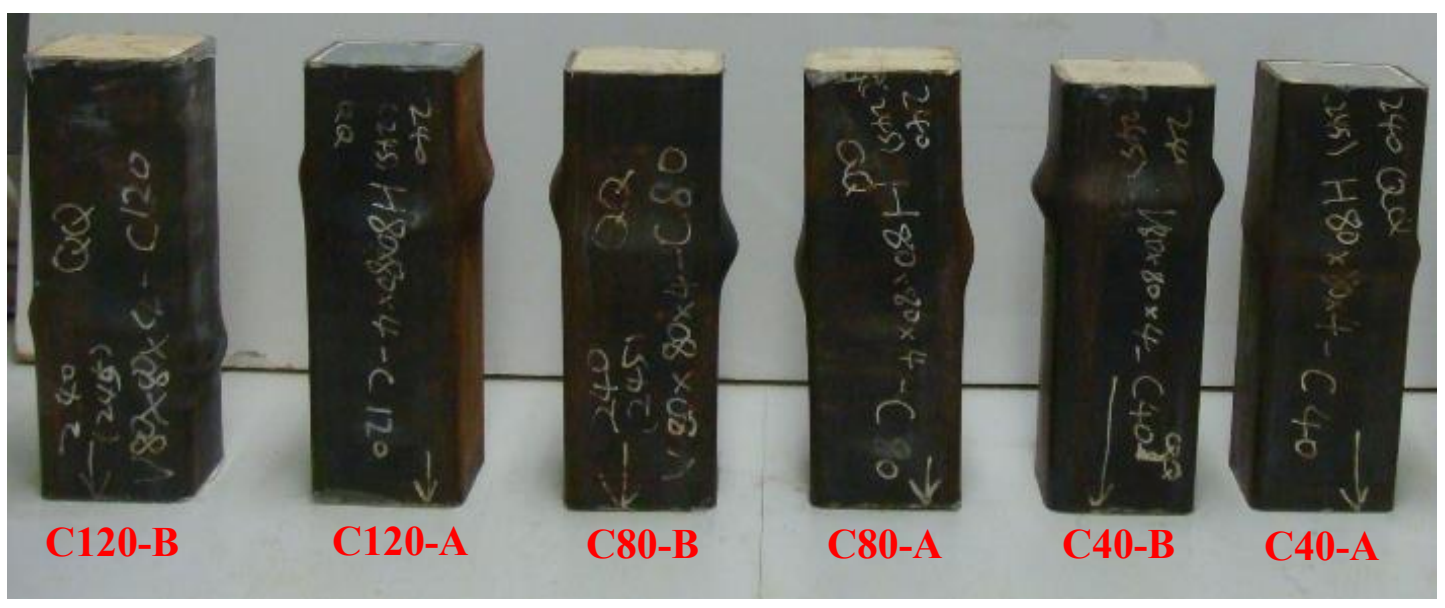

Figure 7: Failure modes of stub columns (series $80 \times 80 \times 4-\mathrm{A}$ and $80 \times 80 \times 4-\mathrm{B}$ ) 

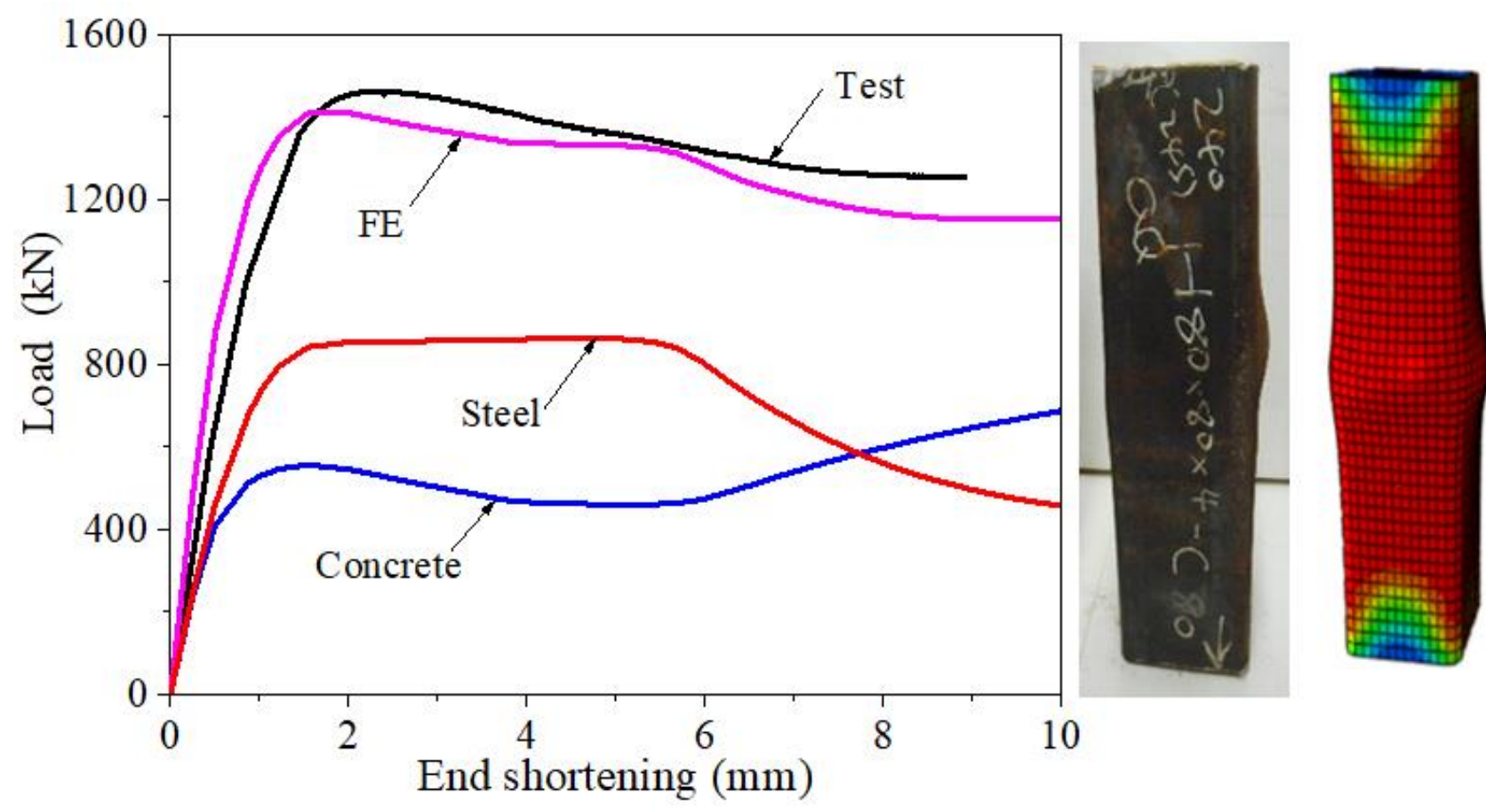

Figure 8: Comparison of test results and numerical predictions for Specimen $80 \times 80 \times 4-\mathrm{C} 80-\mathrm{A}$
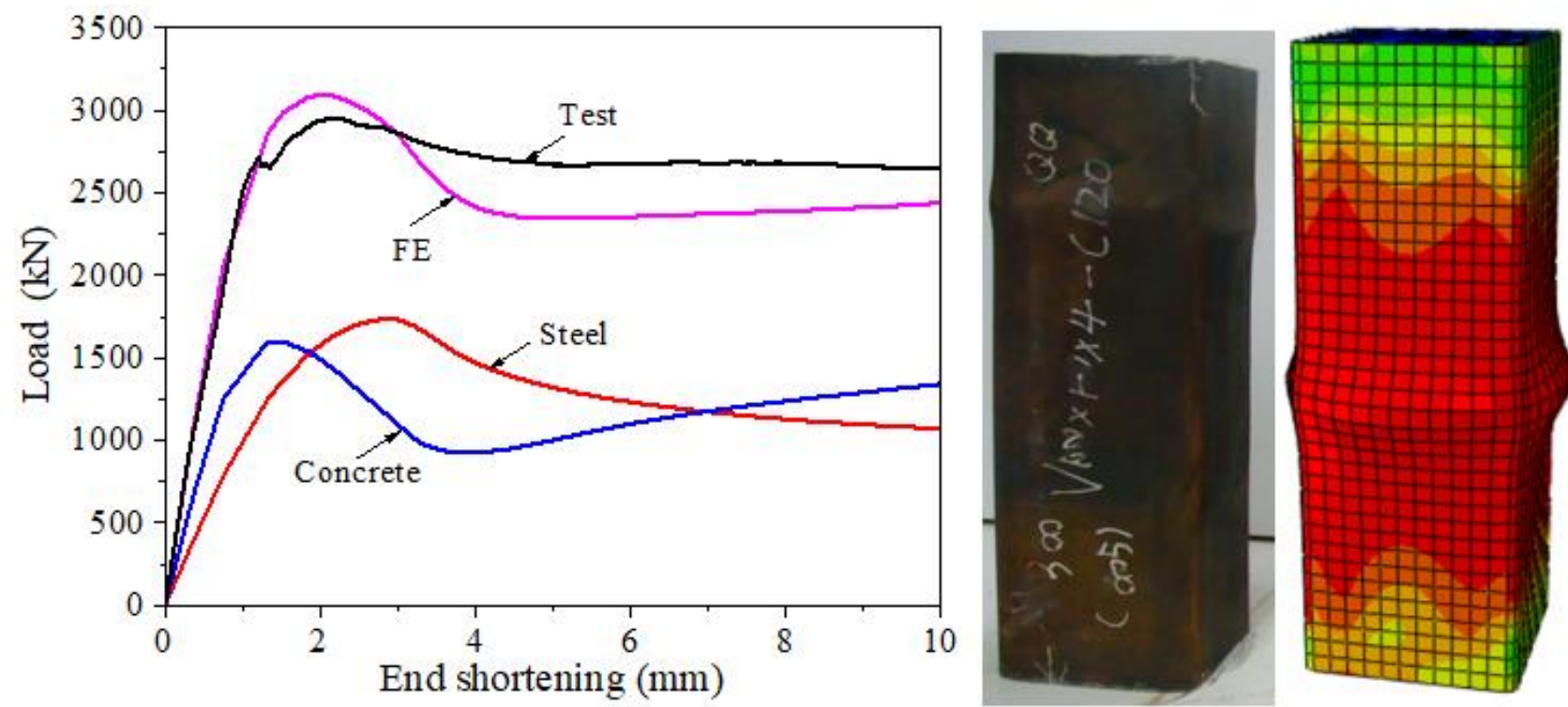

Figure 9: Comparison of test results and numerical predictions for Specimen $120 \times 120 \times 4-\mathrm{C} 120$-B 


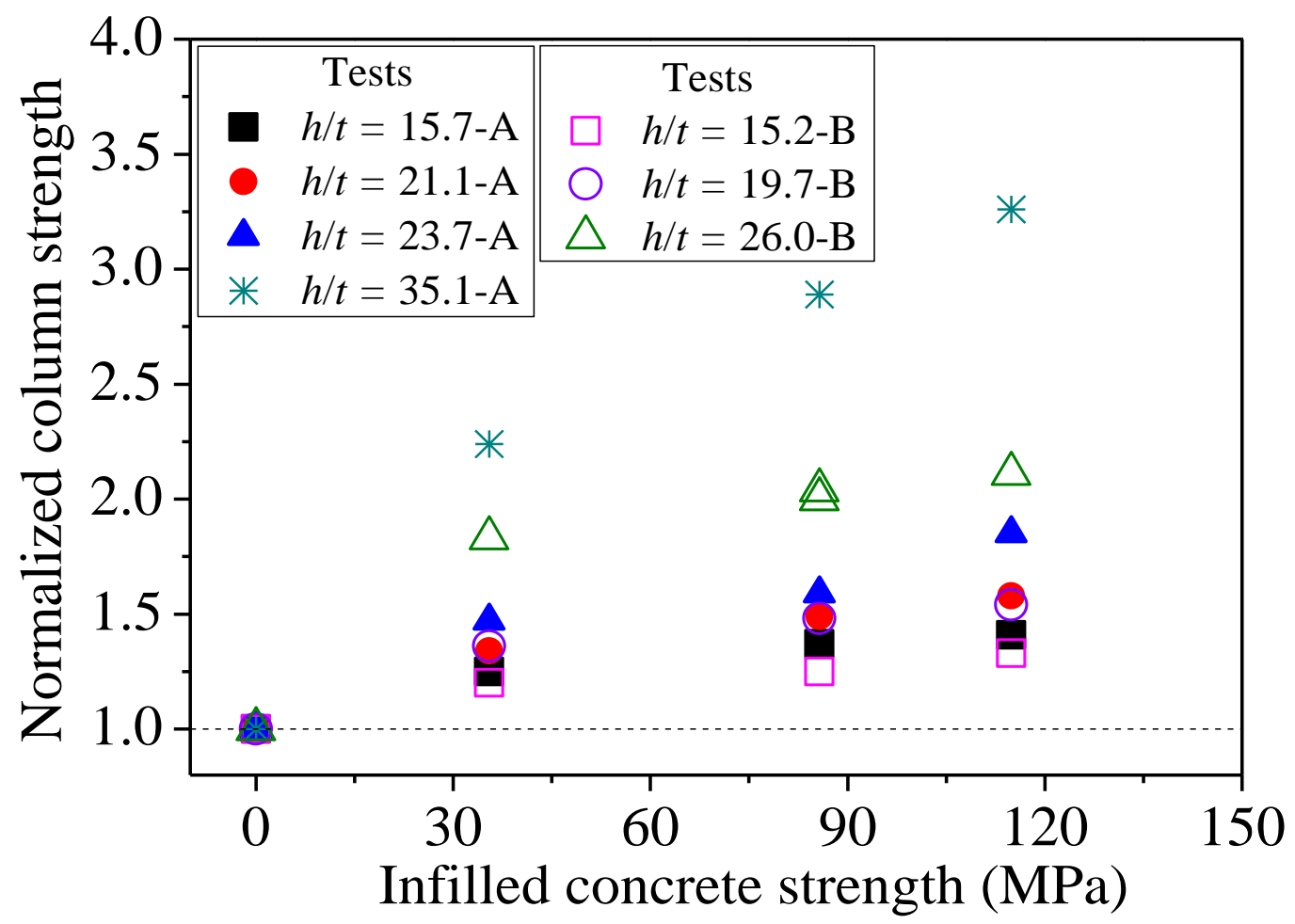

(a) Square sections from test results

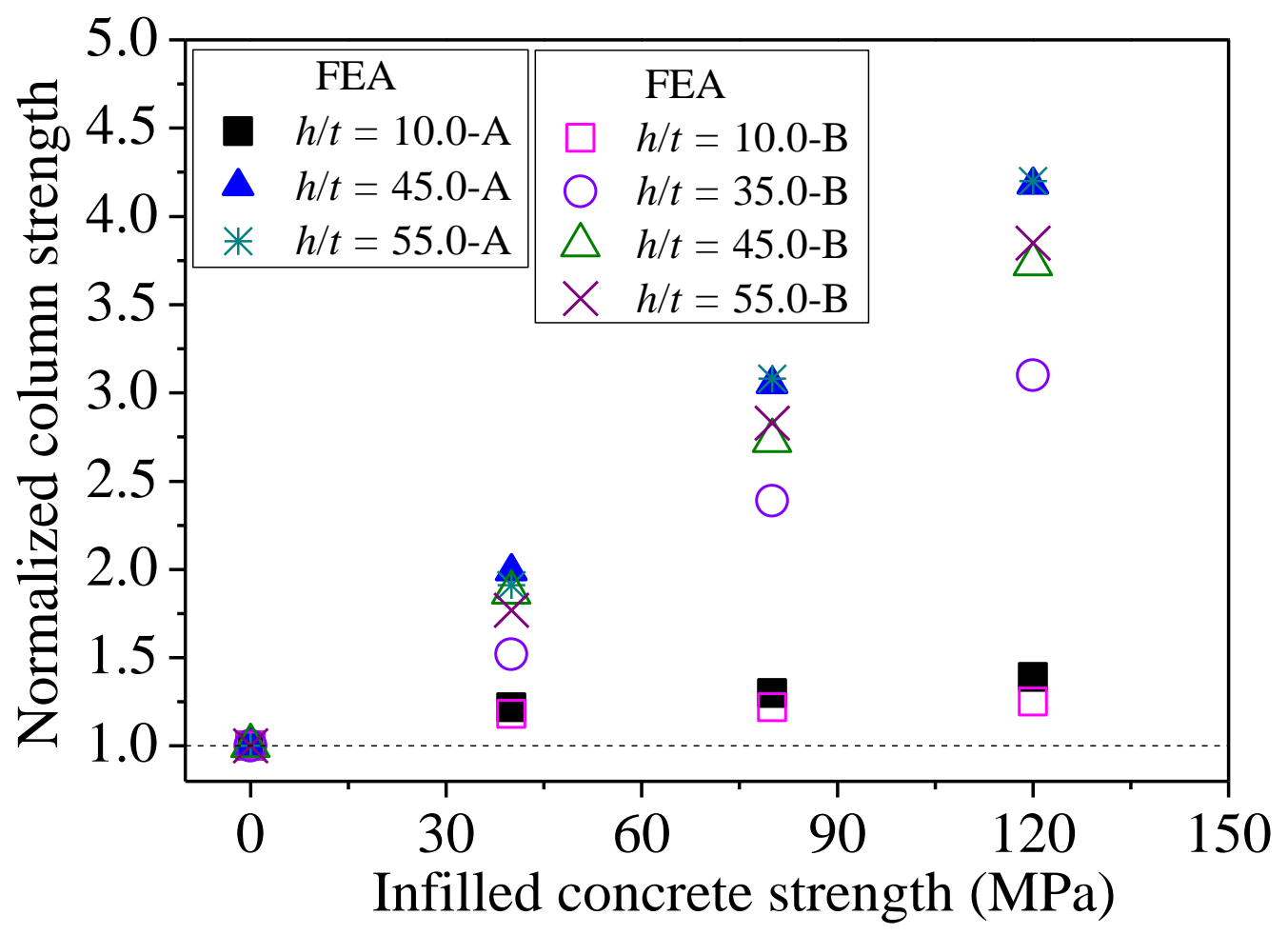

(b) Square sections from FEA results 


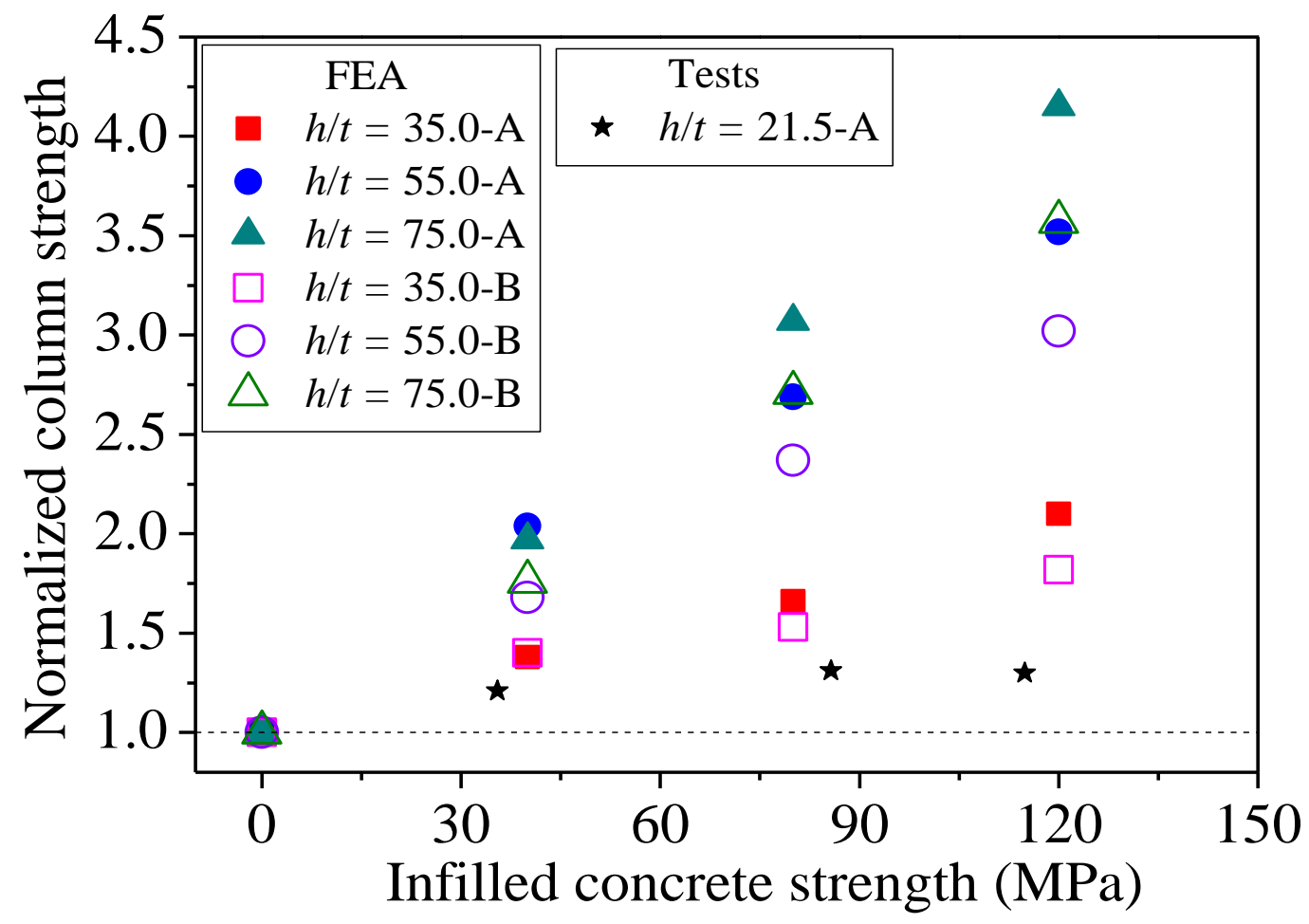

(c) Rectangular sections

Figure 10: Comparison of column strength enhancement with different infilled concrete strengths 


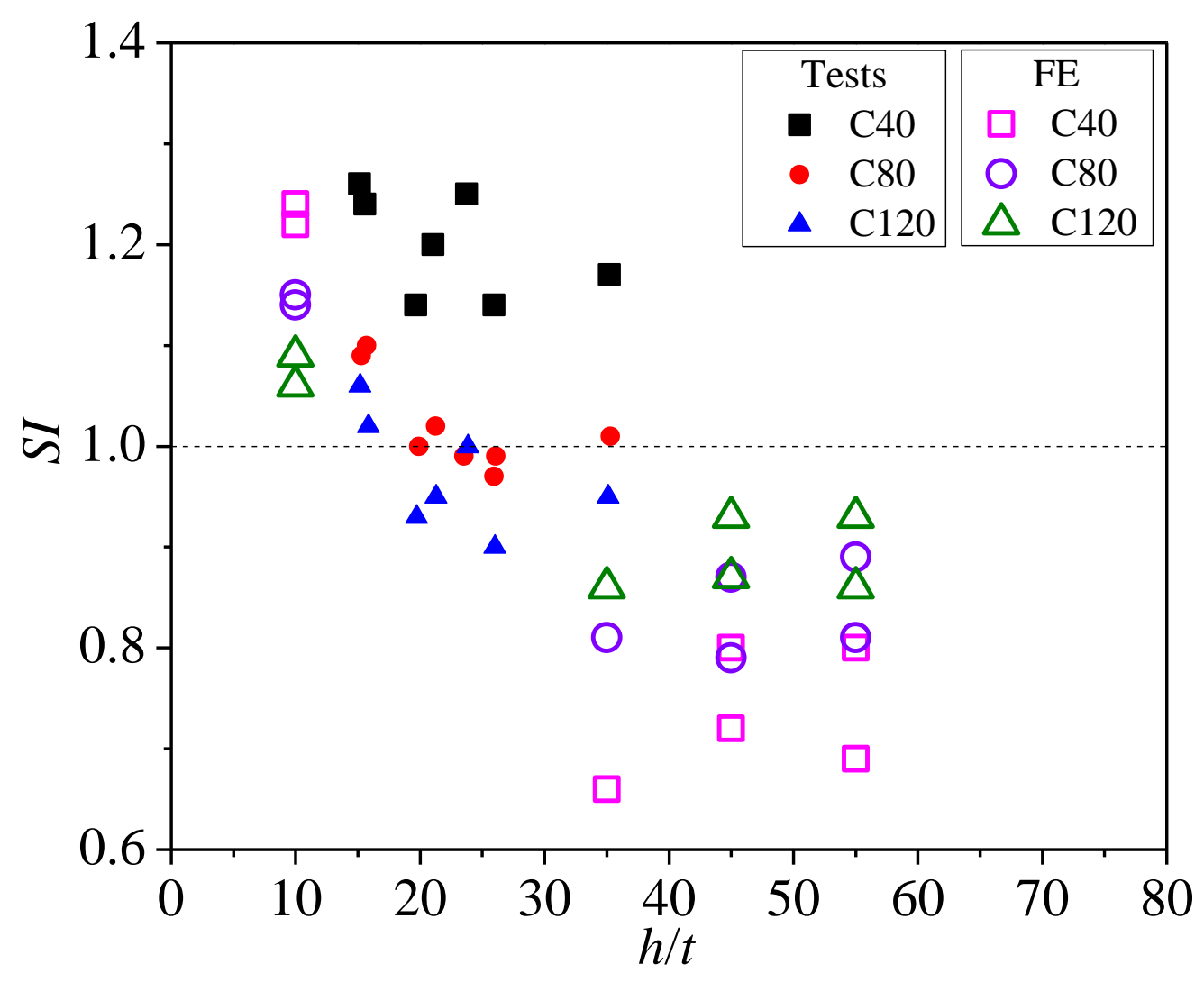

Figure 11: Effects of $h / t$ on $S I$ on concrete-filled CFHSS stub columns with square sections

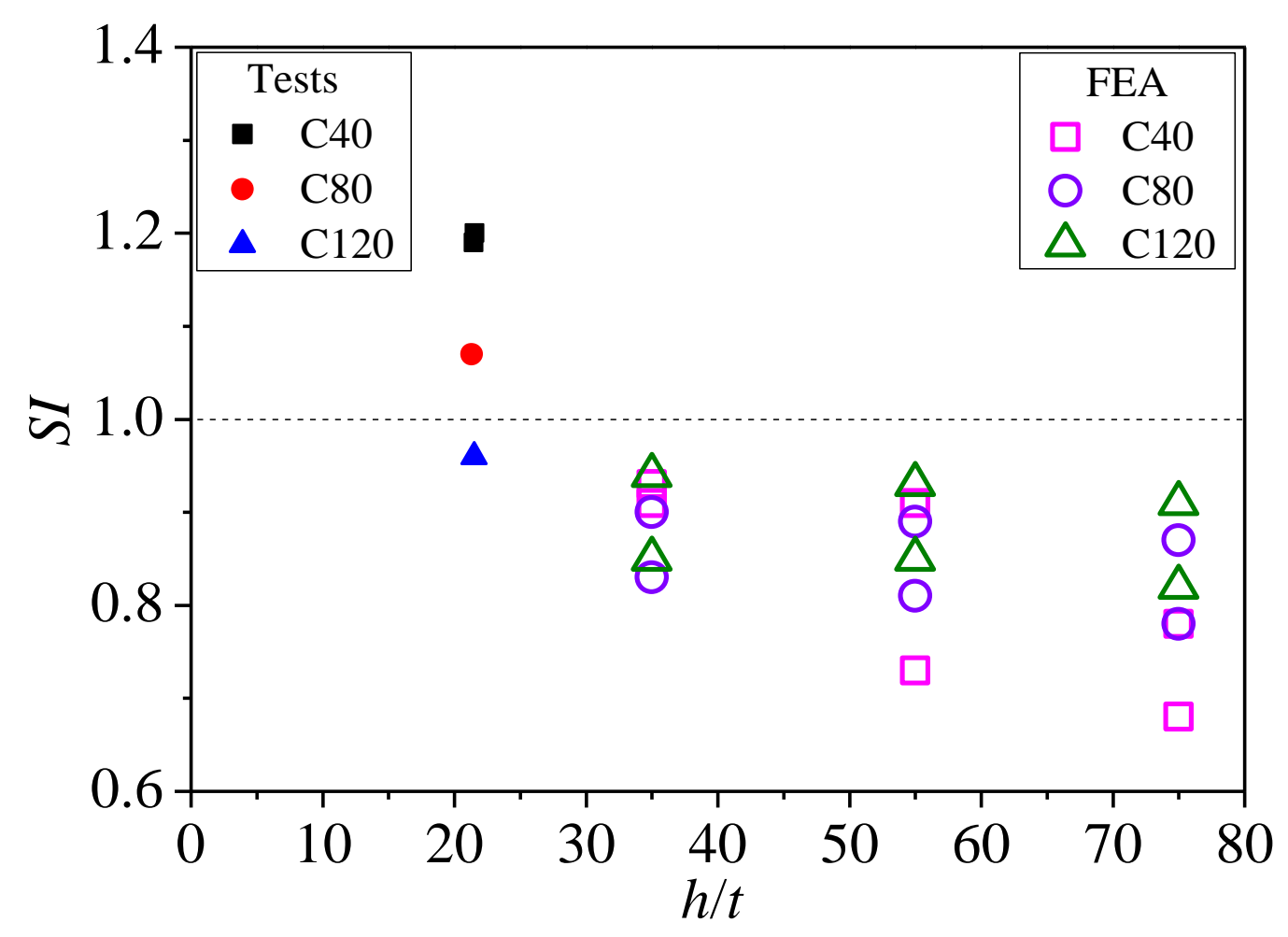

Figure 12: Effects of $h / t$ on $S I$ for concrete-filled CFHSS stub columns with rectangular sections 


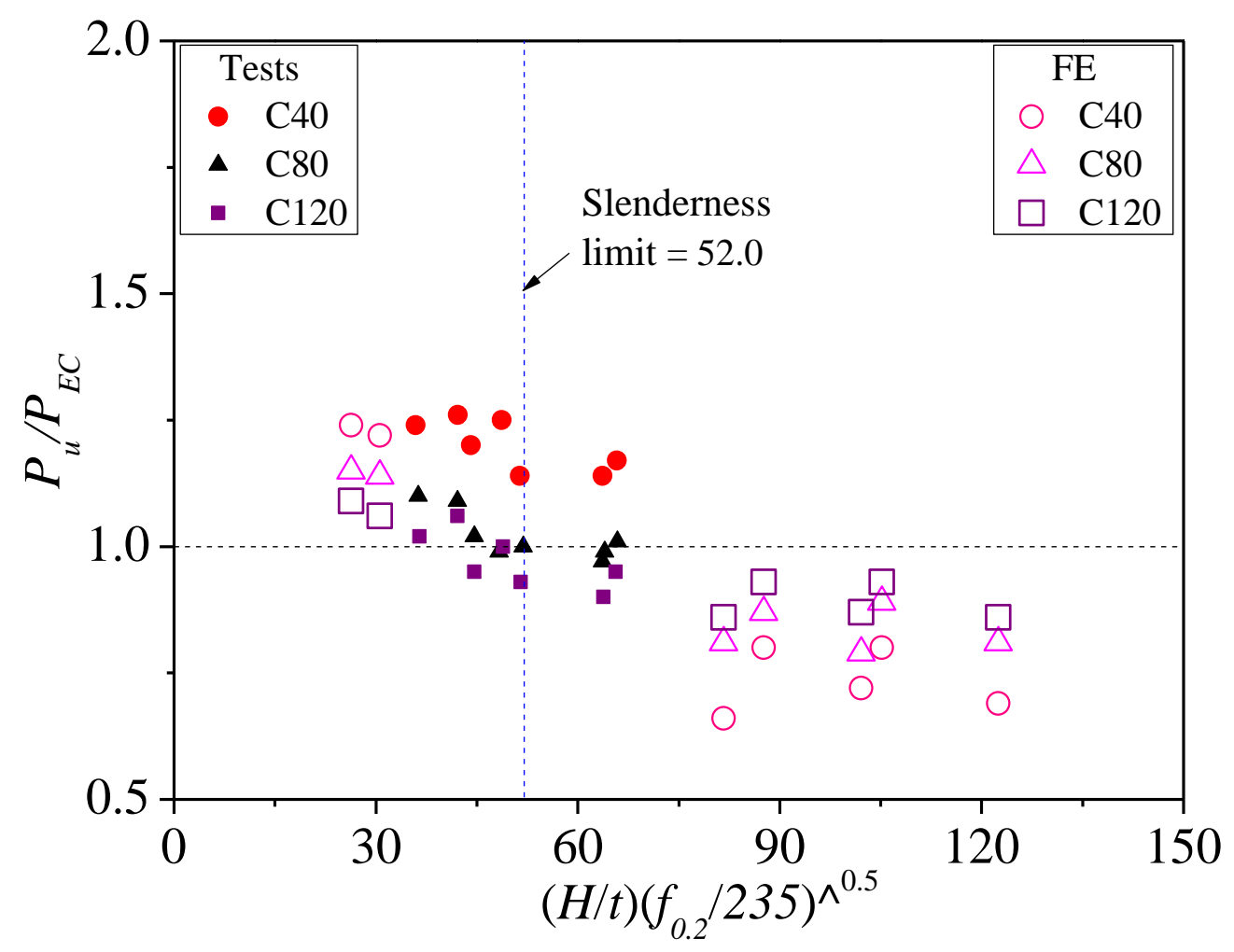

(a) Predictions of $P_{E C}$

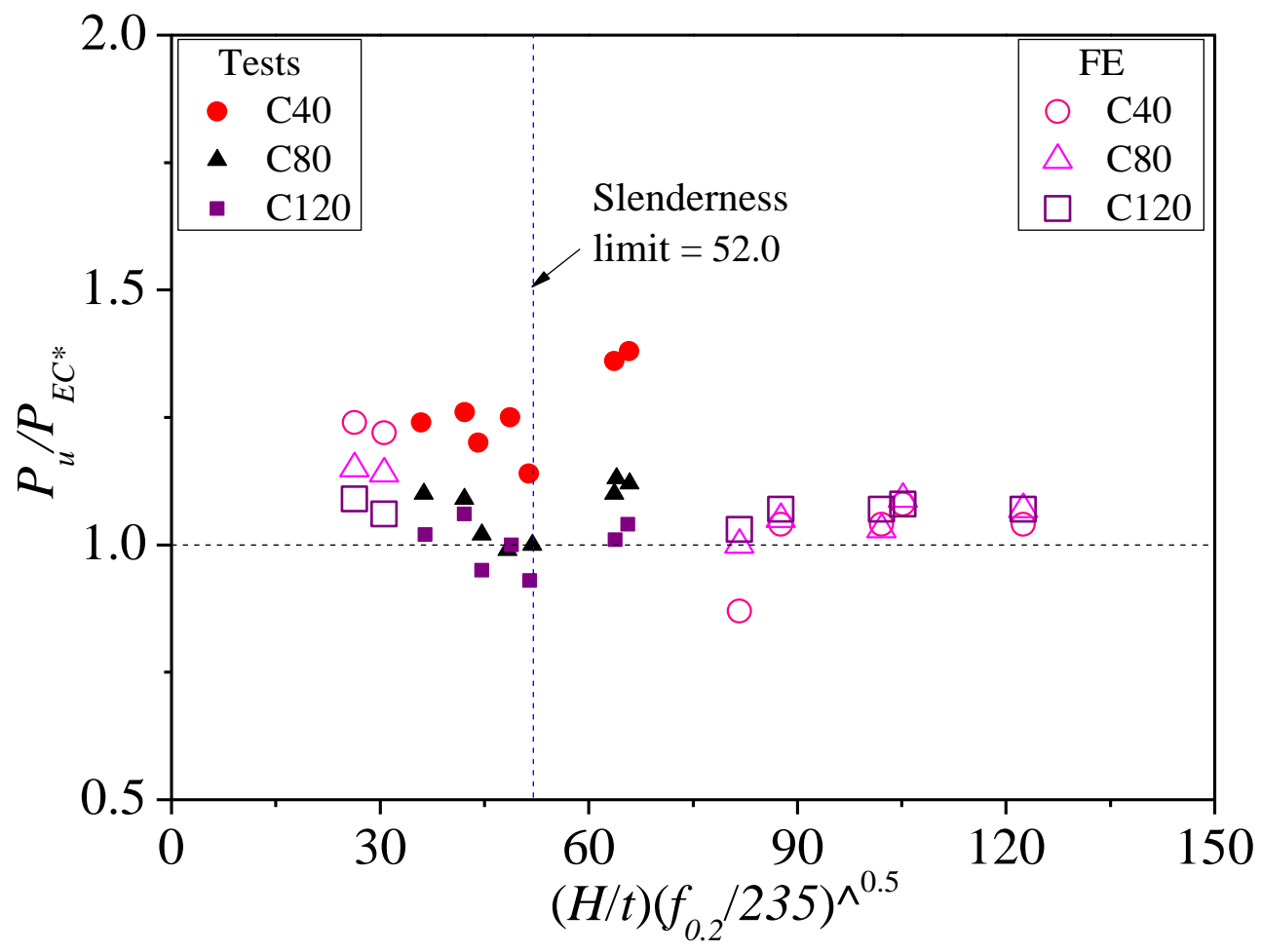

(b) Predictions of $P_{E C} *$ with consideration of effective area 


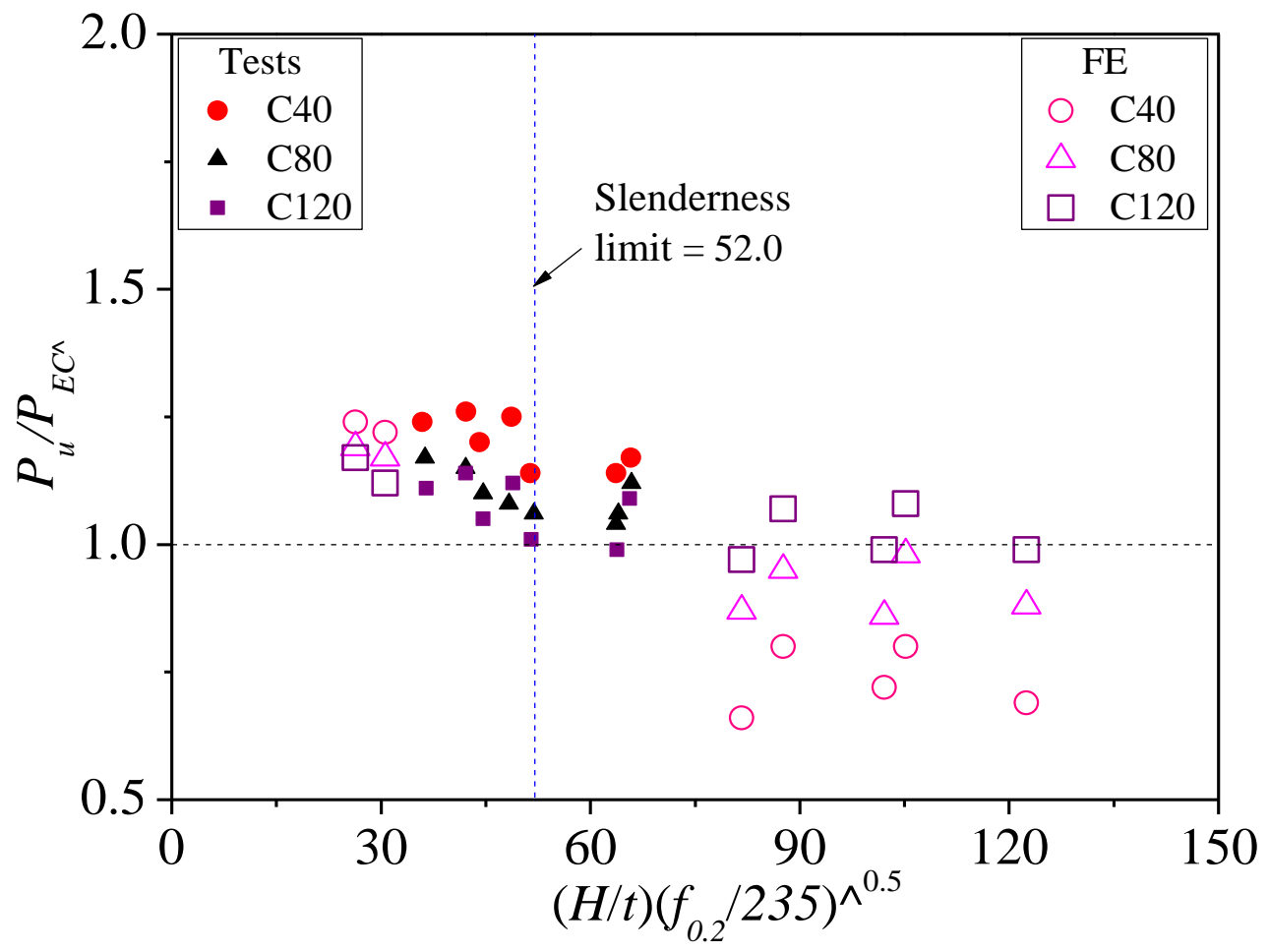

(c) Predictions of $P_{E C^{\wedge}}$ with consideration of effective concrete strength

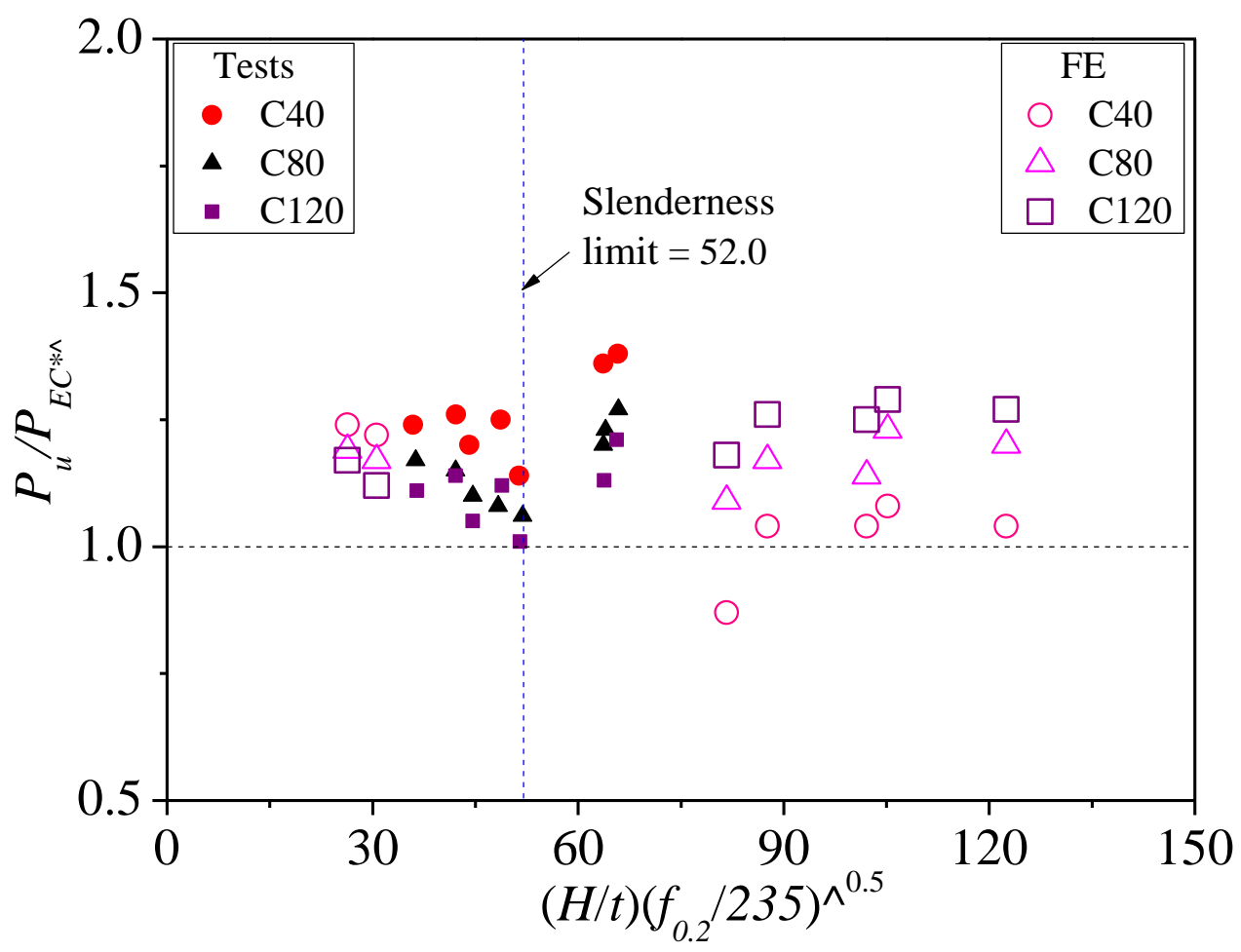

(d) Predictions of $P_{E C^{* \wedge}}$ with consideration of both effective area and effective concrete strength

Figure 13: Assessment of predictions from EC4 [22] for square sections 


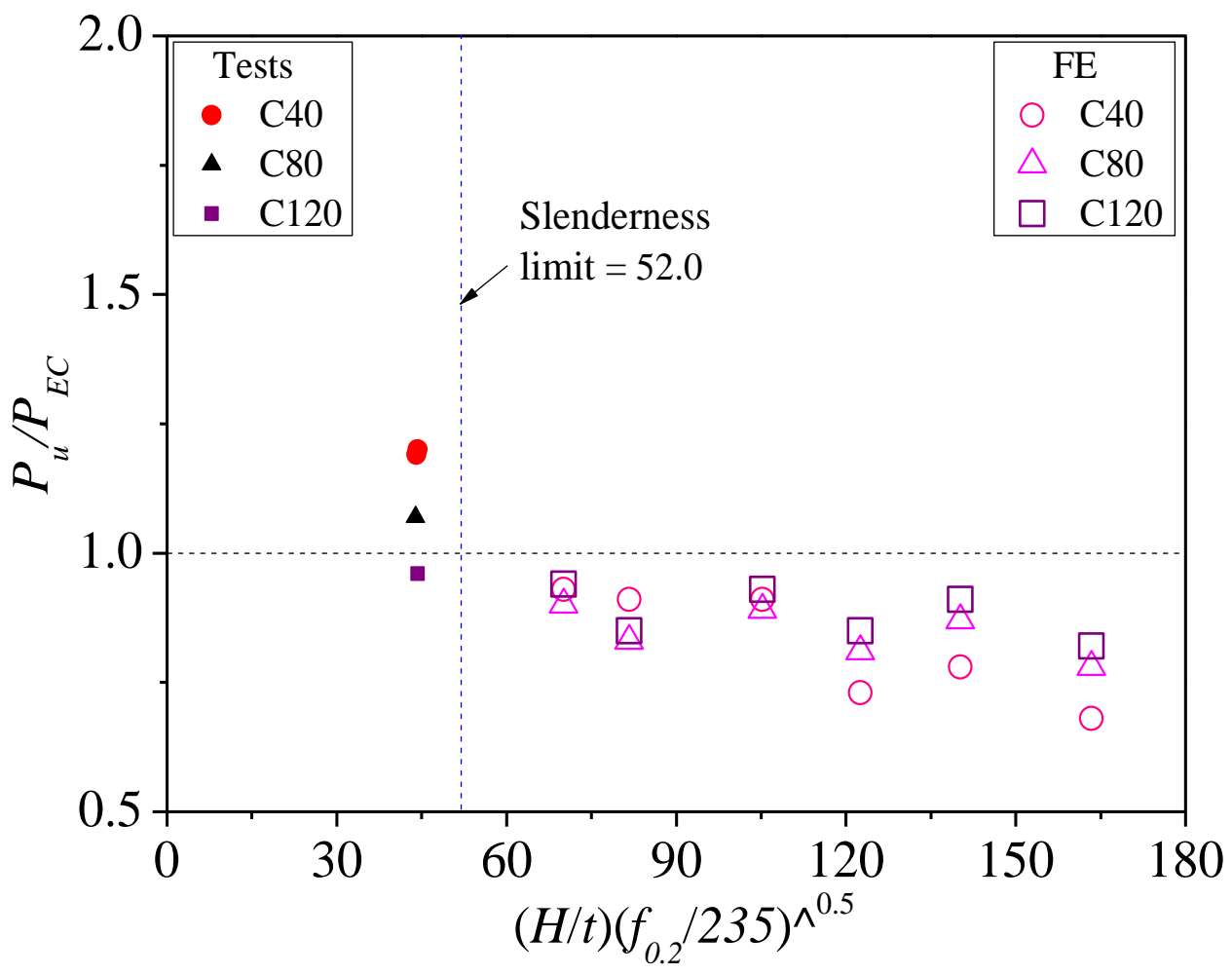

(a) Predictions of $P_{E C}$

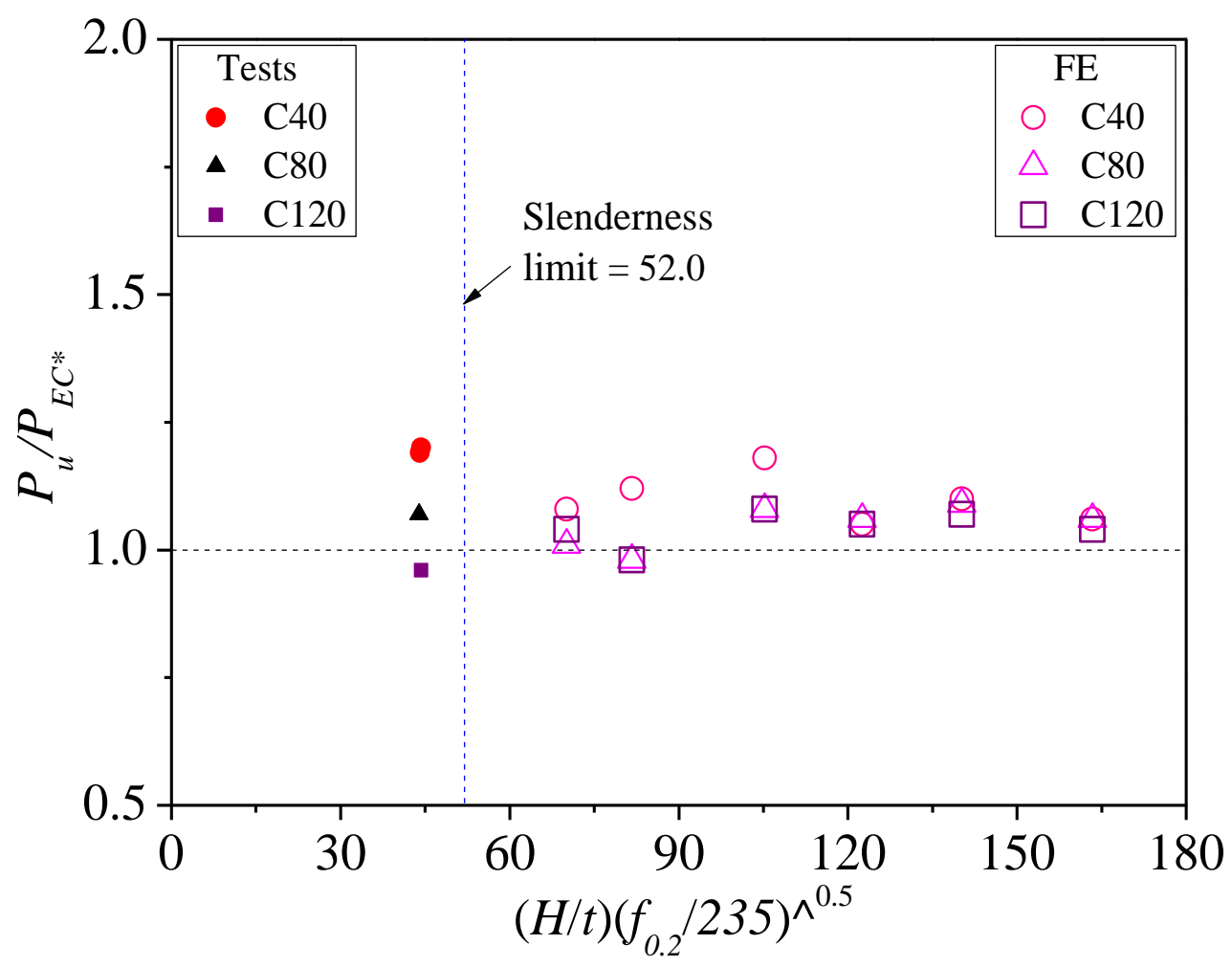

(b) Predictions of $P_{E C} *$ with consideration of effective areas 


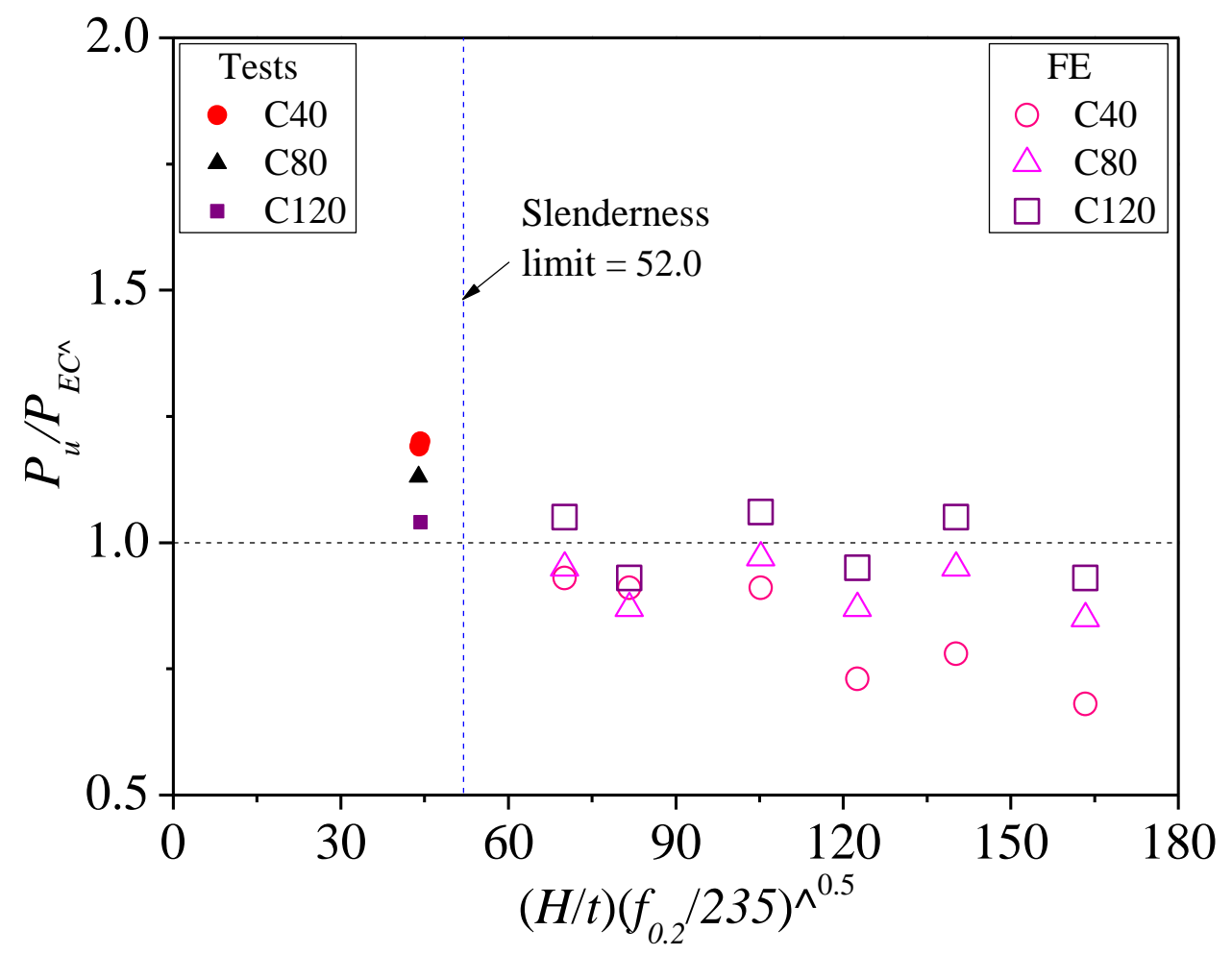

(c) Predictions of $P_{E C^{\wedge}}$ with consideration of effective concrete strength

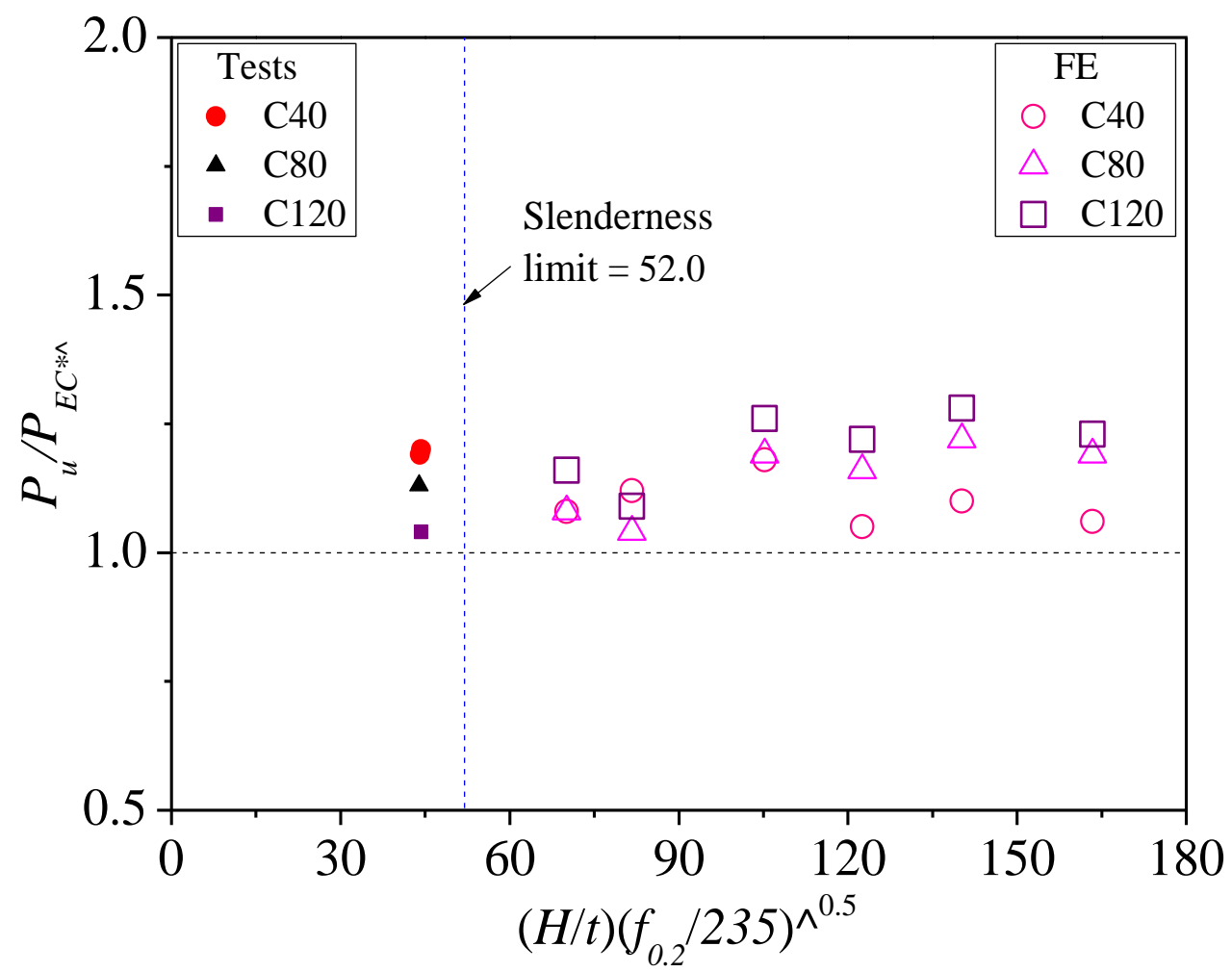

(d) Predictions of $P_{E C^{* \wedge}}$ with consideration of both effective area and effective concrete strength

Figure 14: Assessment of predictions from EC4 [22] for rectangular sections 


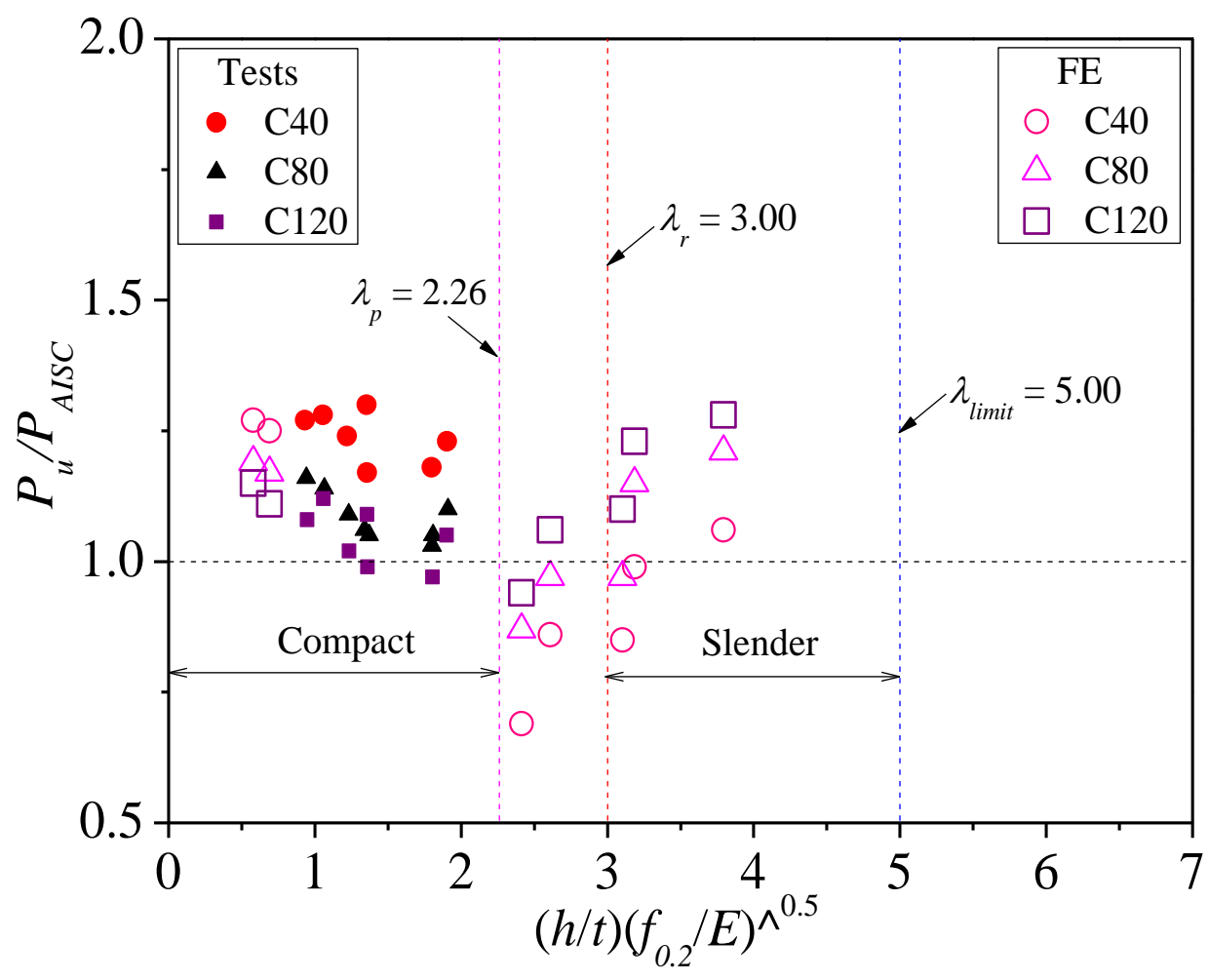

(a) Predictions of $P_{A I S C}$

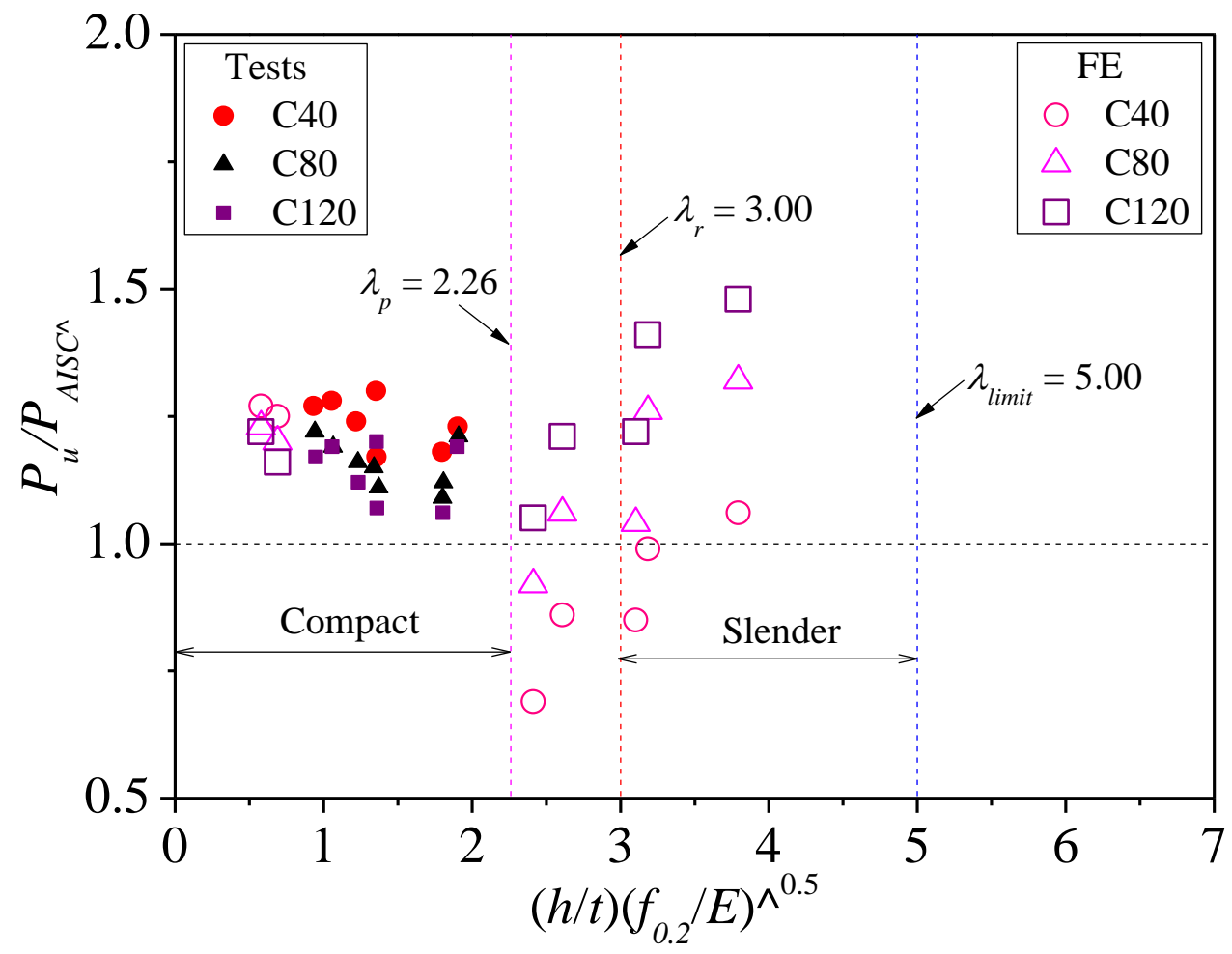

(b) Predictions of $P_{A I S C^{\wedge}}$ with consideration of effective concrete strength

Figure 15: Assessment of predictions from AISC [23] for square sections 


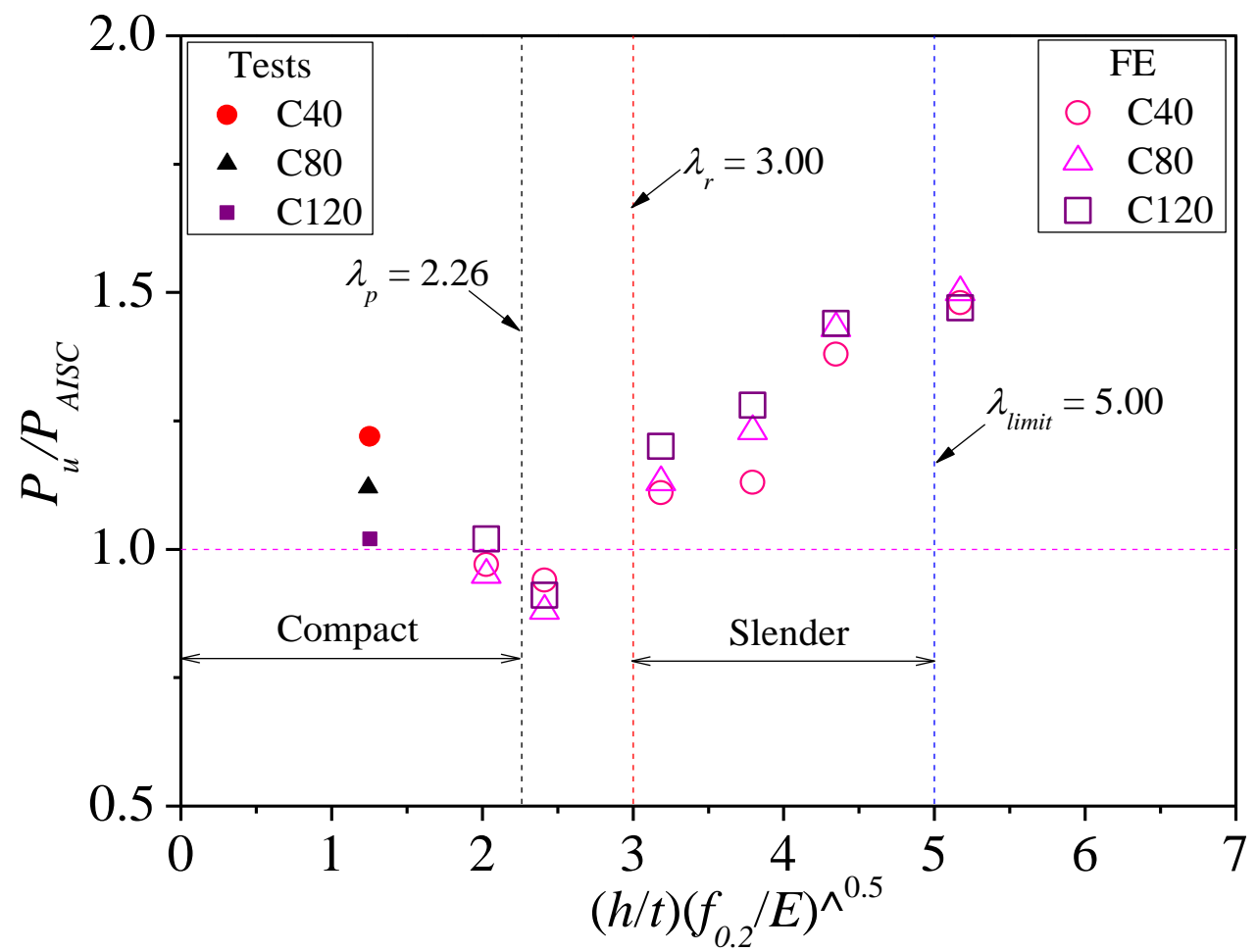

(a) Predictions of $P_{A I S C}$

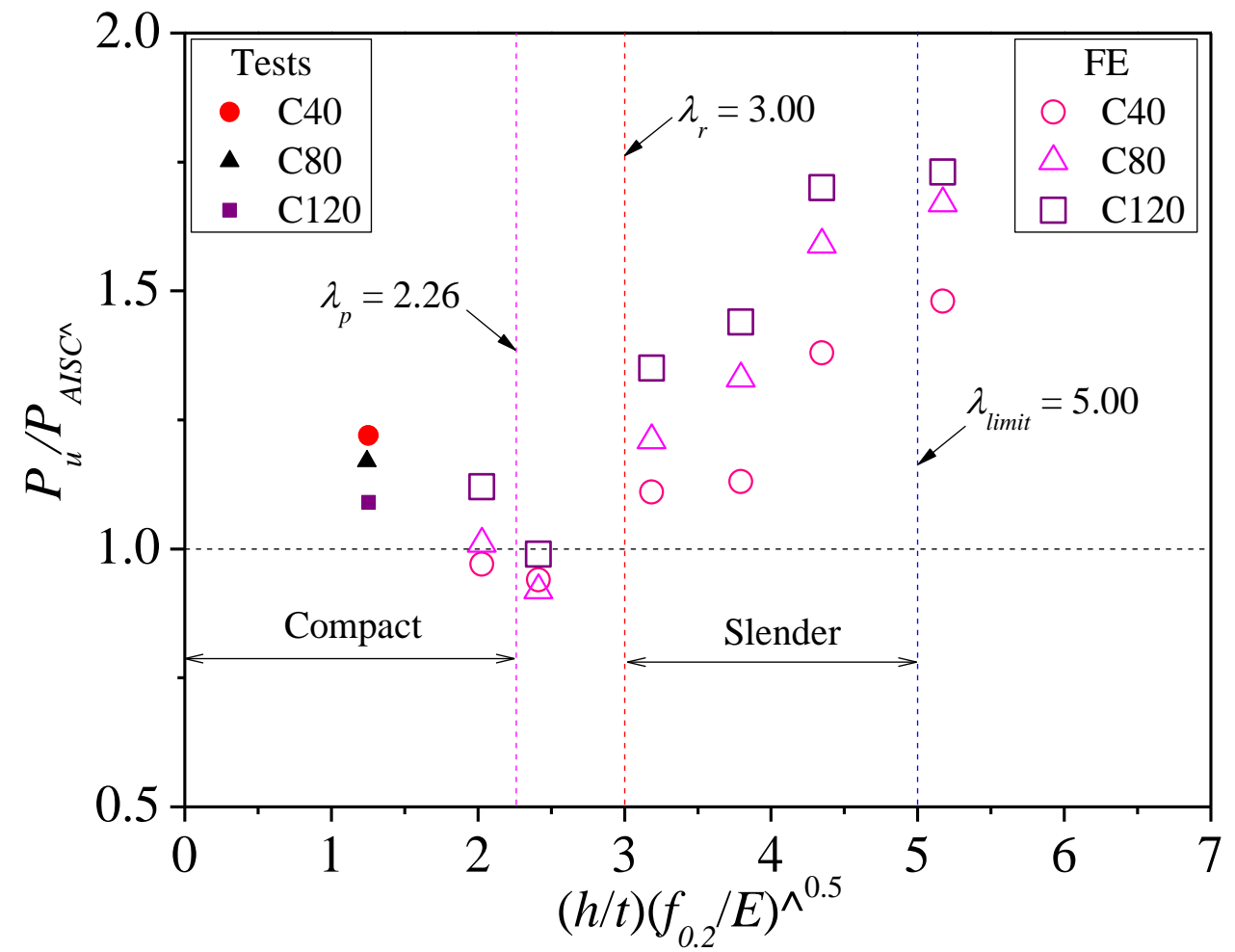

(b) Predictions of $P_{A I S C^{\wedge}}$ with consideration of effective concrete strength

Figure 16: Assessment of predictions from AISC [23] for rectangular sections 